\title{
The Ubiquitin-Proteasome System in Neurodegeneration
}

\author{
Chris McKinnon ${ }^{1} \&$ Sarah J Tabrizi ${ }^{1^{*}}$ \\ Neurology, Queen Square, London, UK. \\ * Correspondence should be addressed to: \\ Sarah J Tabrizi \\ Department of Neurodegenerative Disease \\ UCL Institute of Neurology \\ Queen Square \\ London \\ WC1N 3BG \\ United Kingdom \\ Tel.: +44 845 155 5000/ext. 724434 \\ Fax: +44 2076762180 \\ E-mail: s.tabrizi@ucl.ac.uk
}

${ }^{1}$ Department of Neurodegenerative Disease, University College London Institute of

\author{
Word count: 8,137 \\ References: 213 \\ Colour illustrations: 5 (online 5)
}

Abbreviated title: UPS in neurodegeneration 


\begin{abstract}
Significance: Impairment of the ubiquitin-proteasome system (UPS) has been implicated in the pathogenesis of a wide variety of neurodegenerative disorders including Alzheimer's, Parkinson's and Huntington's diseases. The most significant risk factor for the development of these disorders is aging, which is associated with a progressive decline in UPS activity and the accumulation of oxidatively modified proteins. To date, no therapies have been developed which can specifically upregulate this system.
\end{abstract}

Recent advances: In the neurodegenerative brain, dysfunction of the UPS has been associated with the deposition of ubiquitinated protein aggregates and widespread disruption of the proteostasis network. Recent research has identified further evidence of impairment in substrate ubiquitination and proteasomal degradation which could contribute to the loss of cellular proteostasis in neurodegenerative disease. Novel strategies for activation of the UPS by genetic manipulation and treatment with synthetic compounds have also recently been identified.

Critical issues: Here we discuss the specific roles of the UPS in the healthy central nervous system and establish how dysfunctional components can contribute to neurotoxicity in the context of disease.

Future directions: Knowledge of the UPS components specifically or preferentially involved in neurodegenerative disease will be critical in the development of targeted therapies which aim to limit accumulation of misfolded proteins without gross disturbance of this major proteolytic pathway. 


\section{Introduction}

Efficient folding of nascent polypeptides and rapid elimination of misfolded proteins is critical to the maintenance of cellular and organismal health. Under normal conditions, this protein homeostasis (also known as proteostasis) is achieved by an integrated network of molecular chaperones and proteolytic clearance systems, including the ubiquitin-proteasome system (UPS) and autophagy (79). The UPS is a highly conserved and tightly regulated pathway for the coordinated degradation of a wide variety of proteins with half-lives ranging from minutes to several days (70). It is therefore unsurprising that dysfunction of the UPS has been implicated in the pathogenesis of many human pathologies, including cancer, autoimmunity and neurodegeneration. Despite heterogeneous clinical phenotypes, Alzheimer's, Huntington's and Parkinson's diseases are all characterised by the accumulation of misfolded, aggregate-prone proteins and the pathognomonic accumulation of ubiquitinated conjugates in post-mortem brains of affected patients (Table 1). Studies in animal models indicate that early impairment of the UPS and resulting loss of cellular proteostasis could be primary mediators of neurodegeneration, raising the possibility of proteostasis-based therapies to slow disease progression.

Each neurodegenerative disease has a unique profile of protein aggregate composition and distribution. The most common form of dementia, Alzheimer's disease (AD) is characterised by the appearance of two types of protein deposit: extracellular amyloid plaques and intraneuronal neurofibrillary tangles (NFTs). NFTs are composed of aggregates of hyperphosphorylated tau, whilst the principal component of amyloid plaques is a 40- to 42residue peptide called $\beta$-amyloid protein $\left(A \beta_{1-40}\right.$ and $\left.A \beta_{1-42}\right)$ (161). Parkinson's disease (PD) is classically associated with the selective loss of dopaminergic neurons in the substantia nigra. At the cellular level, PD is characterised by the appearance of eosinophilic cytoplasmic 
inclusions, termed Lewy bodies, which contain aggregated forms of the protein $\alpha$-synuclein (84). In Huntington's disease (HD), translation of a CAG repeat expansion in exon 1 of the HTT gene results in expression of mutant huntingtin $(\mathrm{mtHtt})$ protein with a polyQ expansion in the N-terminal region (157). Increased $\beta$-sheet content of mtHtt promotes the agedependent formation of insoluble protein aggregates in structures known as inclusion bodies (157). Misfolded forms of the $\mathrm{Cu}^{2+} / \mathrm{Zn}^{2+}$ superoxide dismutase SOD1 have been identified in amyotrophic lateral sclerosis (ALS), the most common cause of adult-onset motor neuron disease (20). The G93A mutant form of SOD1 is the most commonly studied protein in cellular and animal models of ALS, and is thought to mediate pathology through a toxic gainof-function. Lastly, prion diseases are a collection of rapidly progressive and, in some cases, infectious neurodegenerative disorders characterised by the conformational rearrangement of a normal host-encoded protein, $\mathrm{PrP}^{\mathrm{C}}$, into the abnormal, aggregate-prone conformer $\mathrm{PrP}^{\mathrm{Sc}}$ (153). Whilst $\operatorname{PrP}^{\mathrm{C}}$ is critical for the templated misfolding of $\operatorname{PrP}$, its depletion is not associated with overt pathology (25). As a result, prion disease pathogenesis is also believed to occur by a toxic gain-of-function of the misfolded conformer.

As the principal route of protein degradation in mammalian cells, the UPS represents a major defence against these misfolded proteins, particularly in post-mitotic neurons which are unable to divide to reduce their burden of damaged proteins. Proteins are marked for proteasomal degradation by covalent conjugation of ubiquitin, a highly conserved 76-residue polypeptide, in a three-step cascade (Fig. 1). Initially, the ubiquitin-activating enzyme, E1, activates ubiquitin by creating a high-energy thiol ester intermediate in an ATP-dependent reaction (80). The activated ubiquitin moiety is subsequently shuttled from E1 to E2, an ubiquitin-conjugating enzyme, creating a second high-energy thiol ester intermediate (80). A third class of enzyme, the ubiquitin E3 ligases, mediate the covalent attachment of 
polyubiquitin chains to an internal lysine residue of specific UPS substrates (70). Similar to other forms of post-translational modification, the process of ubiquitination is reversible under the influence of specific deubiquitinating enzymes (DUBs) (82). Polyubiquitinated proteins are recognised and subsequently degraded by the $26 \mathrm{~S}$ proteasome. This ATPdependent proteolytic complex consists of a 20S core particle and one or two 19S regulatory particle(s) (Fig. 2). The barrel-shaped 20S complex is composed of four heptagonal rings: two identical outer $\alpha$-rings $\left(\alpha_{1-7}\right)$ and two identical inner $\beta$ rings $\left(\beta_{1-7}\right) . \beta_{1}, \beta_{2}$ and $\beta_{5}$ subunits are responsible for peptide bond cleavage, with preference for acidic (caspase-like activity), basic (trypsin-like activity) and hydrophobic (chymotrypsin-like activity) residues, respectively (55). The N-termini of the $\alpha$ subunits function as a gate, restricting substrate entry to the proteolytic chamber (75). The $19 \mathrm{~S}$ regulatory particle is important for the recognition, unfolding and translocation of ubiquitinated substrates into the $20 \mathrm{~S}$ core particle for degradation (11).

In addition to the UPS, protein quality control is also mediated by clearance of misfolded proteins through the autophagic pathway. Autophagy, and more specifically macroautophagy, is responsible for the bulk turnover of redundant cellular constituents, including damaged organelles and protein aggregates. In this highly regulated process, a region of cytosol is isolated in a double membrane-bound structure called an autophagosome, which later fuses with the lysosome to expose sequestered contents to hydrolytic enzymes (140). Extensive cross-talk between the UPS and autophagy has been described, including the compensatory upregulation of autophagy in conditions of UPS impairment (112). Although beyond the scope of this review, defects in autophagy have been reported in the pathology of various disorders including Alzheimer's and Parkinson's diseases, and may be additional source of proteostasis disruption in the neurodegenerative brain (extensively reviewed in (140)). 
In this review, we will evaluate the specific roles of the UPS in the healthy central nervous system (CNS) and discuss how impairment of substrate ubiquitination or proteasomal degradation can lead to loss of cellular proteostasis in the context of neurodegenerative disease. In the absence of effective strategies to upregulate UPS activity, we also highlight possible components of the UPS which may be valid therapeutic targets for the treatment of these debilitating disorders. 


\section{The UPS in the healthy CNS}

Despite being highly conserved across species, structurally and functionally distinct subpopulations of the UPS have been identified in different tissues $(58,71,174)$. This variation has been attributed to alterations in ubiquitin ligase activity, proteasome subunit composition and tissue-specific proteasome-interacting proteins $(58,71,174)$. Following isolation of $26 \mathrm{~S}$ proteasomes from rodent brain, mass-spectrometry identified 28 interacting proteins, of which only 12 were shared with muscle tissue (174). This heterogeneity is likely to reflect marked variation in the cellular proteomes of different tissues and the varying regulatory factors required for their degradation. In order to maintain cellular proteostasis, it is critical that components of the UPS are adapted to meet the specific physiological demands of the tissue (14). In the CNS, synaptic transmission is a critical process by which neurons receive, process and transmit information. A synapse is composed of two distinct functional units: presynaptic terminals and postsynaptic dendritic spines. In the presynaptic terminal, neurotransmitters are packaged in synaptic vesicles which later dock and fuse with specialised regions of plasma membrane called active zones. Exocytosis of neurotransmitters into the synaptic cleft stimulates cell surface receptors localised on dendritic spines of the post-synaptic neuron, activating downstream signal transduction pathways. The UPS has been implicated in the regulation of neurotransmission at pre-and post-synaptic sites, thus playing a critical role in neuronal signalling.

At the presynaptic terminal, the E3 ligase SCRAPPER was shown to ubiquitinate and promote degradation of Rab3-interacting molecule 1 (RIM1), a scaffold protein which links synaptic vesicles to membrane fusion machinery in the active zone (206) (Fig 3). Consistent with a role in the regulation of vesicle exocytosis, SCRAPPER knockout mice display 
impaired RIM1 ubiquitination and dysregulation of synaptic vesicle release (206). At the postsynaptic terminal, the UPS plays a key role in the dynamic remodelling of dendritic spines in response to changes in neuronal activity (57). These structural rearrangements underlie the process of synaptic plasticity, in which synapses are strengthened or weakened in an activity-dependent manner to facilitate processes such as learning and memory. To compensate for excessive neuronal stimulation, post-synaptic excitability can be dampened by reducing the size of dendritic spines and the number of cell surface receptors (19) (Fig 3). For example, in response to synaptic stimulation, the E3 ligase TRIM3 was shown to ubiquitinate and promote degradation of the postsynaptic scaffold protein GKAP, leading to a reduction in dendritic spine size (85). In a similar activity-dependent mechanism, the E3 ligase $\mathrm{SCF}^{\beta-\mathrm{TRCP}}$ was shown to ubiquitinate the Rap GTPase activating protein SPAR, targeting it for degradation (4). As a positive regulator of dendritic spine size, proteasomal clearance of SPAR promotes synaptic shrinkage, tempering postsynaptic activation in conditions of chronically elevated activity (163). Dampening of excitatory synaptic transmission can also be achieved by the internalisation of postsynaptic neurotransmitter receptors (Fig 3). Neuronal activity can induce transcription of the E3 ligase E6-AP which ubiquitinates and controls degradation of Arc, a synaptic protein involved in the internalisation of the AMPA subtype of glutamate receptors (73). Inactivating mutations in the $U B E 3 A$ gene which encodes E6-AP are associated with the neurodevelopmental disorder Angelman syndrome, demonstrating the importance of E3 ligase activity to normal synaptic function $(108,131)$.

Activity-dependent remodeling of dendritic spines requires increased turnover of postsynaptic proteins, a process which is facilitated by an upregulation of proteasome function $(17,57)$. In response to activation of neurotransmitter receptors, influx of calcium 
results in autophosphorylation of the postsynaptic protein kinase CaMKIIa (Fig 3), enhancing its association with proteasomes and directing their relocalisation to dendritic spines (18). In addition to the redistribution of proteasomes, CaMKIIa was also shown to enhance proteolytic activity by phosphorylation of the proteasome subunit Rpt6 (57). This localised upregulation of proteasome activity in spines may be important for the structural remodelling of active synapses. Consistent with this hypothesis, recent work by Hamilton and colleagues demonstrated that CaMKIIa -mediated phosphorylation of Rpt6 was critical to the activity-induced outgrowth of new dendritic spines (78).

Taken together, the above studies support a direct role for the UPS in normal brain function, and in particular, learning and memory. Dysfunction of the UPS would therefore be expected to interrupt activity-induced synaptic plasticity. This effect was elegantly demonstrated by Lopez-Salon and colleagues, who studied the effect of proteasome inhibition on long-term memory formation in rats (124). Avoidance training was associated with increased levels of ubiquitinated proteins and $26 \mathrm{~S}$ proteasome activity in the hippocampus (124). Infusion of the proteasome inhibitor lactacystin in the post-training interval resulted in full retrograde amnesia, demonstrating the critical role of the UPS in memory consolidation (124). In similar experiments, proteasome inhibitors have also been shown to prevent extinction of contextual fear memory (116) and to disrupt the consolidation of spatial memory (6). Efficient turnover of synaptic proteins by the UPS therefore plays a critical role in synaptic plasticity. In the context of neurodegenerative disease, rising levels of misfolded proteins may divert UPS activity away from these critical regulatory functions, leading to impairments in neuronal function. 


\section{The UPS in neurodegenerative disease}

Dysfunction of the UPS in neurodegenerative disease can arise from impairments in ubiquitination, substrate delivery to the proteasome or a loss of proteasome activity (Fig. 4), each of which can contribute to progressive disruption of cellular proteostasis.

\section{(1) Impairments in ubiquitination}

\section{Ubiquitin}

A mutant form of ubiquitin, $\mathrm{UBB}^{+1}$, has been implicated in the pathogenesis of several tauopathies and polyglutamine diseases (117). $\mathrm{UBB}^{+1}$ is generated by a process known as molecular misreading, in which a dinucleotide deletion at the level of ubiquitin mRNA results in a 19 amino acid C-terminal extension (118). In the absence of a Gly76 residue, this frameshift mutant is unable to ubiquitinate other proteins, yet is itself efficiently ubiquitinated. Since the resulting polyubiquitinated $\mathrm{UBB}^{+1}$ is refractory to disassembly by DUBs, it is thought to compete with other polyubiquitinated substrates for recognition and degradation by the proteasome (114). Transgenic mice with postnatal neuronal expression of $\mathrm{UBB}^{+1}$ display a marked reduction in UPS activity, accumulation of ubiquitinated proteins and an early impairment in contextual memory, mirroring the clinical hallmarks of AD (63). A significant proportion of $\mathrm{UBB}^{+1}$ neurotoxicity may, however, be independent of an effect on the UPS since studies in primary neurons revealed that $\mathrm{UBB}^{+1}$ induces dysregulation of mitochondrial trafficking in neurites, leading to mitochondrial stress and activation of p53 cell death pathways (175). Whilst these effects were effectively reversed by $\mathrm{UBB}^{+1}$ silencing, such strategies are likely to have limited therapeutic potential due to the inability to identify clinical cases affected by the accumulation of $\mathrm{UBB}^{+1}$. 


\section{E1/E2 enzymes}

Evidence of impairment in the earliest stages of the ubiquitination process has been identified in post-mortem $\mathrm{AD}$ brain tissue. One study reported a significant reduction in E1 and E2 enzyme activities in human AD brain tissue, which was associated with impaired formation of high-molecular-weight ubiquitin-protein conjugates (123). It remains unclear whether similar deficits are present in other neurodegenerative diseases.

\section{E3 ligases}

Parkin

Mutations in the cytosolic E3 ligase parkin are the most common cause of autosomal recessive monogenic PD (109). In addition to inherited mutations, cysteine residues in the RING domains of parkin are particularly susceptible to oxidation and nitrosylation, which may lead to functional impairment in cases of sporadic PD $(41,205)$. In response to mitochondrial depolarisation, parkin is normally recruited from the cytosol to direct proteasomal degradation of outer mitochondrial membrane (OMM) proteins, including Mitofusins 1/2, Tom 20/40/70 and $\operatorname{Omp} 25$ (31, 176, 210). Depletion of Mitofusins 1 and 2 is thought to prevent mitochondrial fusion, thus segregating dysfunctional depolarised mitochondria from healthy mitochondria. In addition, the degradation of OMM proteins may be an important prerequisite for mitophagy, by exposing inner mitochondrial membrane (IMM) proteins to the cytosol for secondary degeneration. Consistent with these findings, loss of parkin function has been associated with reduced polyubiquitination of OMM proteins, the accumulation of defective mitochondria and increased cell death (190). In addition to its role in substrate ubiquitination, parkin has also been shown to enhance assembly and activity of the $26 \mathrm{~S}$ proteasome $(46,87,186)$. Parkin gene therapy may 
therefore be an attractive strategy to preserve mitochondrial integrity and enhance degradation of misfolded proteins. The potential therapeutic benefit of parkin overexpression may not be restricted to PD as parkin has also been shown to interact with $\mathrm{A} \beta$ and was found to be depleted in post-mortem AD brains (156) . Consistent with these observations, overexpression of wild-type parkin effectively depleted levels of $A \beta_{1-42}$ in $\mathrm{AD}$ cell and rodent models $(27,156)$.

\section{CHIP}

Misfolded proteins must be refolded by molecular chaperones (e.g. Hsc70/Hsp70 and Hsp90) or targeted for degradation by the UPS to prevent aggregation and cytotoxicity. Carboxy terminus of Hsc70-interacting protein (CHIP) is a $35-\mathrm{kDA}$ member of the RING domain family of E3 ligases, which binds to E2 ubiquitin-conjugating enzymes through a C-terminal U-box domain and to Hsc70/Hsp70 and Hsp90 chaperones through an N-terminal tetratricopeptide repeat domain (42). As suggested by its interacting partners, CHIP plays a key role in the ubiquitin-mediated degradation of unfolded chaperone substrates $(42,151)$. One such substrate is LRRK2, a multi-domain protein with kinase and GTPase activities (129). Mutations in LRRK2 are the most common known cause of PD and are associated with the accumulation of $\alpha$-synuclein in intraneuronal aggregates (213). CHIP-mediated clearance of LRRK2 was shown to rescue SH-SY5Y cells from mutant LRRK2 toxicity (110). CHIP has also been shown to promote the degradation of other disease-associated proteins including oligomeric forms of $\alpha$-synuclein (179), hyperphosphorylated tau species (56, 151), mutant SOD1 (187) and $\mathrm{mtHtt}(91,136)$. Overexpression of CHIP protected against $\mathrm{A} \beta$-induced accumulation of tau in a mouse model of $\mathrm{AD}$, suggesting that $\mathrm{CHIP}$ gene therapy could be a general strategy to enhance clearance of misfolded proteins (142). In addition to directly promoting tau clearance by ubiquitination, CHIP may also facilitate its 
degradation by abrogating the protein folding activity of chaperone Hsp90 (43). This could have important wider implications for proteostasis by preventing the functional loss of chaperones through their pre-occupation with folding of aggregate-prone disease-associated proteins.

\section{E6-AP}

The UBE3A gene encodes the HECT-domain E3 ligase E6-AP and was initially identified as the sole causative gene underlying the neurodevelopmental disorder Angelman syndrome $(108,131)$. Recently, a novel role of E6-AP in the context of neurodegeneration has started to emerge. A pronounced depletion in levels of E6-AP was identified in the motor neurons of mutant SOD1 transgenic mice (137) and E6-AP was reported to be a key component of Lewy bodies in postmortem PD brains (139). Recruitment of E6-AP to aggregates may result in a depletion of functional soluble pools, with detrimental consequences for synaptic plasticity. This effect was recently observed in the R6/2 mouse model, where E6-AP recruitment to nuclear huntingtin aggregates was accompanied by decreased levels of AMPA receptors and various pre- and post-synaptic proteins (127). While E6-AP gene therapy has proven effective in ameliorating learning deficits in a mouse model of Angelman syndrome, it remains unclear whether similar strategies would be effective in the context of neurodegenerative disease where no inactivating mutations in $U B E 3 A$ have been identified (49). Elevated levels of E6-AP may still have important neuroprotective effects by maintaining soluble E6-AP pools for the continued regulation of synaptic function. 


\section{Deubiquitinating enzymes (DUBs)}

USP9X

In addition to an age-related decline in proteasome activity, recent evidence suggests that the accumulation of aggregate-prone monoubiquitinated $\alpha$-synuclein in PD brains may be accounted for by a failure of DUB activity. USP9X interacts with and deubiquitinates $\alpha$ synuclein in vitro and was found to be depleted in post-mortem brain tissue of Diffuse LewyBody Dementia (DLBD) and PD patients (158). The development of compounds to activate USP9X may prove useful in promoting deubiquitination of monoubiquitinated $\alpha$-synuclein, reducing aggregate formation and cytotoxicity.

\section{$U C H-L 1$}

Initially identified as a DUB, UCH-L1 has a multitude of reported functions, including ubiquitin ligase activity and the stabilisation of mono-ubiquitin. PARK5, a rare autosomal dominant form of $\mathrm{PD}$, is caused by a missense mutation in $U C H-L 1$ resulting in a $\mathrm{I} 93 \mathrm{M}$ substitution (119). UCH-L1 ${ }^{193 M}$ has increased affinity for LAMP-2A, which may disrupt CMA-mediated turnover of $\alpha$-synuclein and promote nigral cell death $(99,208)$. Proteomic analyses revealed a reduction in wild-type $\mathrm{UCH}-\mathrm{L} 1$ levels in post-mortem AD and PD brains, and identified that the protein is a major target of oxidative damage $(28,37)$. These findings have important implications in the context of sporadic disease as carbonyl-modified UCH-L1 shares similar physicochemical properties to $\mathrm{UCH}-\mathrm{L} 1^{193 M}$ (100). The neuroprotective effect of $\mathrm{UCH}-\mathrm{L} 1$ overexpression was demonstrated in the APP/PS1 mouse model of AD, where it rescued $A \beta$-induced inhibition of LTP and ameliorated associative memory deficits (72). Further evidence of a neuroprotective role of UCH-L1 comes from the identification of the UCH-L1 S18Y polymorphism which has been associated with a significantly lower risk of 
PD (128) and has modest regulatory effects on Huntington's disease age of onset (204). Intrastriatal adenoviral overexpression of $U C H-L 1^{S 18 Y}$ was found to protect mouse nigral neurons against the toxic effects of the MPTP (203). Taken together, these findings suggest that therapeutics aimed at enhancing UCH-L1 function may help to maintain ubiquitin homoeostasis and synaptic plasticity in the context of disease.

\section{Ataxin-3}

Ataxin-3 (Atx3) is a highly conserved DUB with a structured globular N-terminal domain, termed the Josephin domain, and a flexible C-terminal tail (130). The Josephin domain displays ubiquitin protease activity, while the flexible tail encompasses three ubiquitininteracting motifs (UIMs) flanking a polyQ region of variable length. Abnormal expansion of the polyQ region to over 53 glutamines is pathological and causes the autosomal dominant neurodegenerative disorder Machado-Joseph disease (MJD), also known as spinocerebellar ataxia type 3 (SCA3) (125) . In addition to the toxic gain-of-function conventionally attributed to polyQ repeat expansions, one hypothesis suggests that polyQ expansion leads to a loss of Atx3 function, which could have important implications for proteostasis. Expanded Atx3 retains its ability to bind polyubiquitinated substrates but the mutant protein may be less-efficient in substrate binding or proteolysis as it is associated with higher global levels of ubiquitination than the non-expanded form (202). Further work is required to establish specific physiological substrates of Atx 3 and to determine how these interactions are affected by expansion of the polyQ region in the context of disease.

\section{USP14}

Ubiquitin-specific protease 14 (USP14) is a DUB which resides on the $19 \mathrm{~S}$ regulatory particle and plays an important role in substrate deubiquitination and proteasomal gate 
opening $(148,149)$. The ataxia $\left(a x^{J}\right)$ mutation is a spontaneous recessive mutation that results in reduced Usp14 expression in mutant mice, leading to severe growth retardation, resting tremor and hind limb paralysis (201). These neurological deficits could be attributed to impairments in the developmental maturation and function of neuromuscular junctions (16, 34). Compared with wildtype mice, $a x^{J}$ mice showed a $30-40 \%$ reduction in levels of monomeric ubiquitin, suggesting a critical role for ubiquitin homeostasis in synaptic function (3). Consistent with this hypothesis, transgenic complementation of $a x^{J}$ mice with neuronally expressed ubiquitin was sufficient to prevent developmental and functional deficits (33). Whilst disease-associated mutations in USP14 have not been reported, these findings could yield important insights into neurodegenerative disease, where accumulation of ubiquitinated deposits may lead to functional depletion of ubiquitin pools and associated synaptic dysfunction.

\section{(2) Impairments in substrate delivery to the proteasome}

\section{Ubiquilins}

The ubiquitin-like protein family, or ubiquilins, are characterised by an N-terminal ubiquitinlike domain and C-terminal ubiquitin-association domain, implicating them in the delivery of polyubiquitinated substrates to the proteasome for degradation (111). Polymorphisms in the UBQLN1 gene, have been identified as a modest risk-conferring haplotype for the development of $\operatorname{AD}(13,102)$. While studies in other populations have failed to replicate these findings (169), a significant depletion of ubiquilin-1 was reported in late-onset $\mathrm{AD}$ brains, regardless of $U B Q L N 1$ genotype (172). The role of ubiquilin-1 in $\mathrm{AD}$ pathogenesis may be independent of any effect on substrate delivery to the proteasome since ubiquilin-1 
also plays a critical role in APP maturation and processing by controlling K63-linked polyubiquitination of the APP intracellular domain (8).

Mutations in $U B Q L N 2$, another member of the ubiquilin family, are associated with rare, dominantly-inherited X-linked forms of ALS and ubiquilin-2 immunoreactive inclusions have also been identified as a common pathological feature in non-UBQLN2-linked ALS and ALS/dementia cases $(51,52)$. Consistent with a role of ubiquilin-2 in ubiquitinated substrate delivery to the proteasome, expression of mutant ubiquilin 2 in SH-SY5Y cells induced UPS dysfunction (52). Interestingly, overexpression of wild-type ubiquilin-2 enhanced clearance of TDP-43 in vitro, suggesting a possible role for ubiquilin-2 in TDP-43-associated neurotoxicity (30).

\section{VCP}

Valosin-containing protein (VCP) is a type II member of the ATPase associated with diverse cellular activities (AAA+) family of proteins (93). VCP associates with a broad range of polyubiquitinated proteins through its $\mathrm{N}$ - terminal domain, facilitating their extraction from large multimeric complexes for degradation by the proteasome $(48,209)$. VCP mutations have been implicated in sporadic ALS (2), familial ALS (94), Parkinson's disease (171) and the rare hereditary disease Inclusion body myopathy with Paget's disease of bone and frontotemporal dementia (IBMPFD) (196). Depletion or mutation of VCP has been associated with impairments in both the UPS and autophagy $(50,69,95,183)$. A recent study in Drosophila identified a critical role of VCP in proteasome-dependent degradation of Mitofusins1 and 2 and demonstrated that VCP mutations lead to a loss of mitochondrial quality control (107). Depletion of cellular ATP levels may contribute to the loss of UPS activity associated with VCP mutations. 


\section{(3) Impairments in proteasome activity}

\section{Genetic ablation of neuronal $26 \mathrm{~S}$ proteasome activity}

As the terminal step in UPS-mediated protein degradation, dysfunction of the $26 \mathrm{~S}$ proteasome has potentially catastrophic consequences for the maintenance of cellular proteostasis. Genetic ablation studies have elegantly demonstrated the importance of $26 \mathrm{~S}$ catalytic activity to neuronal function and survival. Bedford and colleagues developed conditional genetic mouse models with spatially restricted inactivation of the 19S subunit Psmc1 (Rpt2) in the forebrain or substantia nigra (10). Since Rpt2 directs gate-opening of the $20 \mathrm{~S}$ core particle on arrival of ubiquitinated substrates, this system was able to test the specific role of ubiquitin-dependent degradation by the $26 \mathrm{~S}$ proteasome in targeted brain regions. Depletion of $26 \mathrm{~S}$ proteasomes in the substantia nigra resulted in Lewy-like body formation, axonal die-back and death of dopaminergic neurons, closely mirroring the neuropathology observed in PD patients. Depletion of $26 \mathrm{~S}$ proteasome activity in the forebrain also resulted in a progressive neurodegeneration with widespread neuronal loss and marked learning deficits. Recently, a similar ablation study investigated the effects of conditional knockout of Psmc4 (Rpt3) specifically in motor neurons. Tashiro and colleagues reported that depletion of Rpt3 was associated with progressive motor neuron loss and locomotor dysfunction (178). Surprisingly, the mice also developed neuropathological hallmarks of sporadic ALS, including inclusions immunoreactive for TDP43, FUS, optineurin and ubiquilin-2. These effects were not observed when autophagy was impaired by specific knockout of Atg7 in motor neurons, underlining the central role of the UPS in the maintenance of neuronal proteostasis (178). 


\section{Age-related decline in proteasome activity}

The brain is particularly susceptible to oxidative stress and protein misfolding due to a high rate of oxygen consumption and only low to moderate activities of antioxidant enzymes such as glutathione peroxidase, catalase and superoxide dismutase (59). Several studies have identified an age-related decline in proteasome activity which may account for the late onset of most sporadic and inherited neurodegenerative diseases (132). In human keratinocytes, an age-related decline in proteolytic activity was attributed to a decrease in proteasome number (150) and structural alterations in $20 \mathrm{~S}$ proteasome subunits (26). Similar changes were reported for 26S proteasomes isolated from the lymphocytes of elderly donors (29). Declining proteasome activity can partly be explained by an age-related accumulation of reactive oxygen species (ROS) which result in oxidative modification of proteasome subunits (74). Disruption of $26 \mathrm{~S}$ proteasome structure may be aggravated by the accumulation of aggregate-prone cross-linked proteins which have been shown to inhibit proteasome activity in conditions of oxidative stress (66).

The importance of preserved UPS activity to longevity was recently demonstrated in a transgenic mouse line with ubiquitous expression of the $\beta_{5 t}$ subunit, normally expressed only in the thymus (181). Since the enzymatically less active $\beta_{5 t}$ subunit is preferentially incorporated into $20 \mathrm{~S}$ proteasomes in place of the $\beta_{5}$ subunit, these mice display reduced levels of proteasome activity. Compared with wild-type controls, $\beta_{5 \mathrm{t}}$ mice have significantly elevated levels of polyubiquitinated and oxidised proteins, as well as a marked reduction in life span (181). Whilst the effect of reduced proteasome activity in the brain was not described, the authors reported an early onset of age-related metabolic disorders such as obesity and hepatic steatosis. In the context of neurodegenerative disease, a reduction in 
proteasome activity with age may shift the balance towards accumulation of mutated or aggregate-prone proteins and thus potentiate the onset of cytotoxicity.

\section{Loss of proteasome activity in neurodegeneration}

A reduction in all three proteasome peptidase activities has been reported in the brains of $\mathrm{AD}$ patients $(106,123)$. Similar impairment was also described in the spinal cord of the SOD1 G93A mouse model of familial ALS and sporadic ALS patients $(97,98)$. Whilst total proteasome number appeared unchanged, a decrease in the expression of specific proteasome subunits, including the $\beta_{5}$ catalytic subunit, was reported $(36,96)$. A reduction in all three peptidase activities was also found in the substantia nigra of sporadic PD brains, which may be accounted for by a marked reduction in levels of the $\alpha$ subunits which are critical for the structural integrity of the $20 \mathrm{~S}$ core particle $(134,135)$. Proteasome dysfunction has since been replicated in transgenic and toxin-induced mouse models of PD, suggesting that these observations are unlikely to be an artifact of end-stage disease, post-mortem delay in tissue processing or limited sample size $(32,64)$. The mechanisms underlying proteasome impairment in neurodegenerative diseases remain controversial. A disruption in proteolytic activity may represent a primary mechanism of disease in which direct interactions between misfolded proteins and the proteasome impair its function. Alternatively, secondary effects of neurodegeneration, such as impaired ATP production or oxidative damage, may precipitate a decline in proteasomal activity.

Primary dysfunction of the proteasome

Alzheimer's disease

$A \beta$ peptides are generated as a product of two sequential endoproteolytic cleavage events of amyloid precursor protein (APP) by $\beta$ - and gamma- secretases (164). Growing evidence 
supports a role of soluble $\mathrm{A} \beta$ oligomers in $\mathrm{AD}$ neurotoxicity, including impairment of learning and memory function (reviewed in (193)). The triple-transgenic mouse model 3xTgAD expresses three major genes associated with familial AD (APP ${ }_{S w e}, \mathrm{PS}_{\mathrm{M} 146 \mathrm{~V}}$ and tau $\left.\mathrm{p}_{\mathrm{p} 301 \mathrm{~L}}\right)$ and develops plaque and tangle pathology which recapitulates that observed in AD patients (141). Treatment of $3 \times \mathrm{Tg}-\mathrm{AD}$ mice with the proteasome inhibitor epoxomicin was found to accelerate accumulation of $A \beta$, suggesting the disease-associated protein is the subject of proteasomal degradation (184). Despite being catalytic substrates, misfolded A $\beta$ species have also been shown to impair proteasome activity. A direct interaction between synthetic A $\beta$ oligomers and purified human 20S core particle was sufficient to inhibit all three peptidase activities (184). Consistent with these in vitro observations, A $\beta$ immunotherapy effectively reversed the age-dependent decline in proteasome activity in the $3 \times \mathrm{Tg}-\mathrm{AD}$ mice (184). The cellular mechanism underlying this effect remains unclear since $A \beta$ is produced in the secretory pathway and must gain cytosolic access in order to interact directly with proteasomes (192).

Tau is an abundant axonal cytosolic protein which associates with and stabilises microtubules. Phosphorylation of tau disrupts its interaction with microtubules and hyperphosphorylated forms of tau have been identified as a key component of paired-helical filaments (PHFs), the building blocks of NFTs commonly associated with AD neuropathology (89). A positive correlation between the number of NFTs and the duration and severity of $\mathrm{AD}$ has been reported (5). Tau can be degraded by a wide variety of cellular degradation systems including calpains, lysosomes and proteasomes. As a natively unfolded protein, tau can be degraded by the $20 \mathrm{~S}$ proteasome without the need for ubiquitin modification (76), however a ubiquitin-dependent pathway has also been described. In cooperation with Hsc70, CHIP facilitates ubiquitin-dependent degradation of abnormal forms 
of tau, including hyperphosphorylated tau $(56,151,167)$. These findings suggest that the UPS may play a selective role in the degradation of abnormal forms of tau, rather than normal soluble tau (88). Tau has also been found to interact directly with proteasomes in human AD brains (105). Incubation of isolated proteasomes with PHFs resulted in a marked reduction in proteasome activity (105). Taken together, these findings suggest that the accumulation of tau and $A \beta$ may contribute to the overall reduction in UPS degradative capacity in human $\mathrm{AD}$ brains and emphasise that strategies to upregulate proteasome activity may be beneficial in aiding clearance of these misfolded protein species.

\section{Parkinson's disease}

Autosomal dominant cases of PD are associated with point mutations (A30P, A53T or E46K) in the SNCA gene which encodes $\alpha$-synuclein (21). By combining in vivo pharmacologic and multiphoton imaging strategies, Ebrahimi-Fakhari and colleagues demonstrated that the UPS is the major degradation pathway for the clearance of endogenous and overexpressed levels of $\alpha$-synuclein in the living mouse brain (61). In contrast, autophagy was only recruited to degrade $\alpha$-synuclein when levels of the protein were massively increased. In vitro studies have provided conflicting accounts on the relative importance of the UPS and autophagy to the degradation of mutant forms of $\alpha$-synuclein $(191,197)$. These variable results are likely a result of different $\alpha$-synuclein expression levels and cell culture conditions, which can have a marked effect on the proteolytic processing of $\alpha$-synuclein.

Since $\alpha$-synuclein knockout mice lack an overt phenotype which resembles PD, mutated forms of the protein are thought to be associated with a toxic gain-of-function (1). Stable overexpression of mutant $\alpha$-synuclein was shown to impair proteasomal function in several mammalian cell lines $(60,62)$, a transgenic mouse model (32) and a novel zebrafish model of 
Parkinson's disease (152). In PC12 cells, soluble, intermediate size oligomers of mutant $\alpha$ synuclein were found to co-elute with the $26 \mathrm{~S}$ proteasome and were associated with a significant inhibition of its catalytic activity (62). Several studies have also reported a direct physical interaction between aggregated forms of $\alpha$-synuclein and the proteasome $(121,170$, 212). Zhang and colleagues demonstrated that $\alpha$-synuclein protofibrils, but not monomeric or dimeric species, bound purified $26 \mathrm{~S}$ proteasome and resulted in a marked inhibition of ubiquitin-dependent and -independent proteasomal degradation (212). Due to the large size of the protofibrils relative to the narrow $20 \mathrm{~S}$ channel pore, this inhibitory effect could result from allosteric inhibition of substrate translocation or sequestration of proteasomal substrates prior to their degradation. Since impairment of proteasome activity can reduce $\alpha$-synuclein solubility, a positive feedback loop may be established in PD whereby mutant $\alpha$-synuclein inhibits the proteasome, leading to further accumulation of misfolded protein species and additional suppression of proteasome activity (60).

\section{Amyotrophic lateral sclerosis}

More than 150 autosomal dominant mutations have been identified in the gene encoding SOD1, which together account for up to $25 \%$ of familial ALS cases (20). Misfolded wildtype SOD-1 has also been identified in sporadic ALS which represents more than $90 \%$ of disease cases $(22,65)$. Misfolded forms of SOD1 are not typically associated with a loss of antioxidant enzyme activity, suggesting that a toxic gain-of-function is likely to be the primary mechanism of pathology (188). Accumulation of SOD1 ${ }^{G 93 A}$ in immortalised motor neurons resulted in marked inhibition of proteasome activity, as measured by the reporter substrate $\mathrm{YFPu}(45,160)$. Using double transgenic SOD1 ${ }^{G 93 A}$ mice which express the proteasome reporter substrate $\mathrm{Ub}^{\mathrm{G} 76 \mathrm{~V}}$-GFP, Cheroni and colleagues identified UPS dysfunction in the spinal and cranial motor neurons of symptomatic mice (35). The 
appearance of the reporter was attributed to reduced expression of catalytic and non-catalytic proteasome subunits, however these effects were observed after the onset of other pathological hallmarks such as mitochondrial swelling and disrupted axonal transport. The identification of UPS dysfunction as a late-stage effect in ALS is supported by data suggesting that detergent-insoluble mutant SOD1 only becomes ubiquitinated after its aggregation in the spinal cord of SOD $1^{G 93 A}$ mice (9). As previously described for $\alpha$ synuclein, inhibition of the proteasome is associated with an exponential increase in levels of insoluble aggregated SOD $1^{G 93 A}$ (160). Thus, late impairment of the proteasome in ALS may contribute to the severe neurotoxicity which ultimately overwhelms motor neurons at endstage disease.

\section{Huntington's disease}

Prior to its degradation, huntingtin (Htt) is phosphorylated by IKK, activating the protein for ubiquitination and subsequent clearance by the proteasome and lysosome (180). Expansion of the Htt polyQ repeat may reduce the efficiency of this phosphorylation, leading to impaired clearance and accumulation of mtHtt. Early in vivo studies in the conditional HD94 (54) and double transgenic R6/2 ubiquitin-reporter mouse models $(15,133)$ reported that the UPS remained functionally active in HD. These findings appeared to contradict the marked accumulation of polyubiquitin chains in the brains of R6/2 mice and human HD patients, including Lys-48 linked conjugates which have been established as the proximal substrates of proteasomal proteolysis (12). This apparent controversy was elegantly resolved by Ortega and colleagues who crossed inducible HD94 mice with $\mathrm{Ub}^{\mathrm{G} 76 \mathrm{~V}}$-GFP proteasome reporter mice to show transient dysfunction of the UPS shortly after induction of mtHtt expression, which was reversed on formation of inclusion bodies (145). Prevention of aggregate formation with the drug riluzole blocked this recovery, suggesting that inclusion body 
formation may be an important neuroprotective response against proteotoxic stress. Wang and colleagues have also reported synapse-specific loss of proteasome activity in R6/2 mice by measuring peptidase activity in isolated synaptosomes and by fusing synaptic targeting sequences to the GFPu proteasome reporter (194) .

One possible explanation for observed UPS dysfunction in HD is that aggregate-prone polyQ proteins become trapped in the channel of the $20 \mathrm{~S}$ core particle, blocking access to other ubiquitinated substrates. This theory was recently dismissed by the observation that ubiquitinated mtHtt, whether aggregated or not, did not clog purified 26S proteasomes (81). Instead, proteasomes may become sequestered into polyQ aggregates, supported by evidence of an increase in proteasome activity in the insoluble cellular fractions of mtHtt-Q150 expressing neuronal cells (92) and the spatial restriction of proteasomes within aggregates in Fluorescence Recovery After Photobleaching (FRAP) experiments (83). Whilst proteasome sequestration may contribute to UPS dysfunction, it is unlikely to play a major role since a large proportion of the neuronal proteasome population remains "free". Recently, Hipp and colleagues proposed a theory of global proteostasis network dysfunction in which rising concentration of $\mathrm{mtHtt}$ causes delayed maturation of other cellular chaperone-clients, promoting their ubiquitination and proteasomal degradation (81). Subsequent competition between increasing numbers of ubiquitinated substrates may result in UPS dysfunction, independent of any impairment in proteasome activity.

\section{Prion diseases}

Although the critical pathological event in prion pathogenesis is thought to be the templated conversion of soluble $\operatorname{PrP}^{\mathrm{C}}$ into insoluble aggregate-prone $\operatorname{PrP}^{\mathrm{Sc}}$, the mechanisms underlying neurotoxicity remain unclear. The brains of prion-infected mice have increased levels of 
ubiquitin conjugates, which correlate with a reduction in proteasome catalytic activities (103). Prion infection of neuroblastoma cells and transgenic mice expressing the proteasome reporter substrate $\mathrm{Ub}^{\mathrm{G} 76 \mathrm{~V}}$-GFP revealed functional impairment of the UPS (113). Incubation of purified 26S proteasomes with semipurified $\mathrm{PrP}^{\mathrm{Sc}}$ from diseased brains or recombinant $\beta$ sheet rich forms of PrP resulted in a marked reduction in all three peptidase activities (113). Similar impairment was not observed when purified 26S proteasomes were incubated with recombinant $\operatorname{PrP}$ folded into a predominantly $\alpha$-helical structure similar to that of $\operatorname{PrP}^{\mathrm{C}}$. A direct interaction between the 20S core particle and misfolded PrP isoforms was found to stabilise the closed conformation of the substrate entry channel, inhibiting the translocation of ubiquitinated substrates into the catalytic chamber for degradation (53). These findings contradict a recent study which reported no evidence of UPS impairment in transgenic mice expressing mutant, albeit non-infectious, PrP isoforms associated with inherited prion diseases (154). This apparent discrepancy may be explained by differences in the subcellular trafficking pathways of different PrP isoforms, which play a critical role in determining whether misfolded PrP species gain access to the cytosol to interact with the proteasome.

Secondary dysfunction of the proteasome

As an ATP-dependent process, the efficiency of ubiquitinated substrate degradation by the 26S proteasome is inextricably linked to mitochondrial respiration. MtHtt was shown to interfere with the association of microtubule-based transport proteins with mitochondria, leading to a reduction in mitochondrial trafficking (144). Consistent with these observations, reduced ATP content has been detected in synaptosome fractions prepared from the brains of HD knock-in mice $(144,194)$. Early aberrations in mitochondrial structure and function have also been reported in the SOD $1^{G 93 A}$ mouse model of ALS (126). In addition to impaired ATP 
production, dysfunctional mitochondria are major sources of oxidative stress through the production of ROS (185). Treatment of neuroblastoma cells with rotenone, an inhibitor of mitochondrial complex I, resulted in impairment of proteasome activity and a secondary decline in levels of the $20 \mathrm{~S}$ core particle $(40,166)$. Taken together, these findings suggest that mitochondrial dysfunction may contribute to UPS impairment in neurodegenerative disease by depleting critical ATP levels and inducing oxidative damage of proteasome subunits. 


\section{Therapeutic strategies to enhance UPS activity}

\section{(1) Enhance ubiquitination}

\section{Maintenance of ubiquitin reserves}

In the human brain, $82 \%$ of processed ubiquitin is found as free monomer, which may function as an important reserve for the rapid degradation of misfolded proteins in conditions of cell stress (101). In neurodegenerative disease, the accumulation of ubiquitinated protein aggregates may result in "trapping" of ubiquitin molecules, depleting ubiquitin reserves with detrimental effects on ubiquitin-dependent proteolysis (77). Consistent with this theory, mouse models of ubiquitin depletion are associated with a severe neurodegenerative phenotype $(3,159)$. Strategies to augment ubiquitin levels may help to protect against progressive proteostasis disruption. Levels of free ubiquitin could be stabilised by overexpression of UCH-L1, which has been shown to bind monoubiquitin with high-affinity and increase ubiquitin half-life in cultured cells and mice (146).

\section{Upregulation of E3 ligase activity}

In addition to the stabilisation of ubiquitin reserves, ubiquitin-dependent proteolysis could be enhanced by upregulation of E3 ligase activity. Parkin gene therapy may be an effective strategy to mitigate neuronal toxicity associated with the accumulation of misfolded forms of $\alpha$-synuclein, particularly in autosomal recessive forms of PD characterised by loss of function mutations in the PARKIN gene (138). Injection of a recombinant adeno-associated viral vector carrying parkin cDNA (rAAV1-parkin) successfully reduced accumulation of $\alpha$ synuclein when co-expressed in the striatum of macaque monkeys (207). The E3 ligase CHIP is another important regulator of ubiquitination and could represent a gene therapy target for the treatment of various neurodegenerative diseases. In a cell culture model of PD, 
overexpression of CHIP reduced levels of $\alpha$-synuclein by promoting its proteasomal and lysosomal degradation (168). In cell culture models of HD and MJD, overexpression of CHIP increased the proteasomal degradation of polyQ-expanded huntingtin and Atx3, respectively $(91,200)$. The potential therapeutic benefit of CHIP overexpression in vivo was demonstrated in the 3xTg-AD mouse model where injection of a CHIP-expressing lentivirus rescued animals from $\mathrm{A} \beta$-induced tau pathology (142).

Modulation of E3 ligases is an attractive therapeutic approach since the specificity of ligasesubstrate interactions can restrict effects to a single cellular pathway, rather than the UPS as a whole. Despite this, traditional methods of gene overexpression by viral delivery of cDNA can be limited by compensatory changes in protein networks or a lack of spatiotemporal control. As a result, small-molecule modulators that modify protein activity at the posttranslational level may be preferable alternatives. Proteolysis targeting chimeric molecules, or PROTACs, are small heterobifunctional molecules designed to induce the degradation of specific target proteins by the UPS (162). PROTACs comprise two distinct recognition motifs separated by a linker moiety. One motif recognises the target protein of interest; the other recognises a specific E3 ligase, enhancing ubiquitination and proteasomal degradation of the selected target protein. This technology has proved effective in the selective degradation of hormone receptors in prostate and breast cancer cells, leading to growth arrest in G1 and ultimately apoptosis (155). Similar approaches may enable the selective proteolysis of disease-associated misfolded proteins in neurons; however further development of PROTAC molecules will be required prior to testing in animal models and humans. 


\section{(2) Enhance proteasome activity}

As previously discussed, impairment in proteasome activity has been reported in postmortem brain or spinal cord tissue from patients with $\operatorname{AD}(106,123), \operatorname{PD}(134,135)$ and ALS (97). Faced with rising levels of misfolded proteins, proteasomal insufficiency may become the rate-limiting step in the UPS, leading to a backlog of ubiquitinated proteins. As a result, strategies to enhance substrate ubiquitination may have limited therapeutic potential, particularly in patients with established neurodegenerative disease. An alternative strategy is to induce activity of the $26 \mathrm{~S}$ proteasome, enhancing clearance of toxic misfolded proteins to ensure that cellular proteostasis is maintained.

\section{$20 S$ core particle induction}

Despite an abundance of small molecule inhibitors of the proteasome, effective methods of upregulation of the proteasome remain scarce. To date, strategies to enhance proteasome activity have predominantly focussed on the genetic upregulation of specific proteasome subunits, however a small number of compounds have been identified which can stimulate proteolytic activity in vitro. Early evidence that proteasome activity could be increased came from genetic manipulation of $20 \mathrm{~S}$ core particle subunits. Goldberg and colleagues observed that lymphoblasts and HeLa cells transfected with the inducible $\beta_{5 \mathrm{i}}$ subunit had increased chymotrypsin- and trypsin-like peptidase activity (68). Transfection of the inducible $\beta_{1 \mathrm{i}}$ subunit into the same cell lines resulted in a selective increase in trypsin-like activity. Later work by the same group reported an increase in caspase-like activity following overexpression of the constitutive $\beta_{1}$ subunit in HeLa cells (67). Interestingly, such genetic manipulation of a single proteasome subunit appears to be sufficient to drive changes in the proteasome complex as a whole. Chondrogianni and colleagues reported that stable overexpression of the $\beta_{5}$ subunit in W138/T and HL60 cells resulted in upregulation of the 
other $\beta$-type subunits and recruitment of "free" $\alpha$-type subunits to increase the number of assembled 20S complexes (39). Evidence of co-regulation of proteasome subunit levels was also observed when $\beta_{5}$ was overexpressed in lens epithelial cells and aged human fibroblasts $(86,122)$. The resulting increase in proteolytic activity enhanced the clearance of oxidised proteins and promoted cell survival. These findings were replicated by overexpression of the POMP proteasome accessory protein in human fibroblast cultures, suggesting that the ratelimiting step in proteasome activity may be $20 \mathrm{~S}$ core particle assembly, rather than the expression level of individual proteasome subunits (38). Taken together, these studies confirm that activation of the proteasome is feasible by genetic manipulation of $20 \mathrm{~S}$ proteasome subunits or proteasome accessory proteins.

\begin{abstract}
Stimulation of proteasome activity in vitro has also been reported following treatment with various natural compounds, including some fatty acids such as olein, linoleic and linolenic acids, as well as oleuropein isolated from Olea europaea leaves (47, 104, 195). These compounds are thought to activate the proteasome through structural changes that promote opening of the 20S gate. Synthetic peptidyl alcohols, nitriles, $p$-nitroanilides and esters were also shown to stimulate proteasome catalytic activity, possibly through interaction with the PA28 activator binding site (199). In most cases, the mechanisms underlying compoundmediated activation of the proteasome remain unclear, limiting their use for research or therapeutic purposes.
\end{abstract}

\title{
19S/11S regulatory particle induction
}

Consistent with their role in activation of the $20 \mathrm{~S}$ core particle, upregulation of various subunits of the $19 \mathrm{~S}$ or $11 \mathrm{~S}$ regulatory particles has been shown to enhance proteasome activity. PA28, also known as the $11 \mathrm{~S}$ regulatory particle, can consist of a heteroheptamer of 
PA2 $8_{\alpha}$ and PA28 $8_{\beta}$ subunits or a homoheptamer of PA28 $\gamma$ subunits. Ectopic expression of PA28 $\gamma$ was shown to recover proteasome function in HD patient fibroblasts and improved survival in mtHtt-expressing striatal neurons in conditions of excitotoxic stress (165). In Drosophila, overexpression of the 19S subunit Rpn11 delayed the age-related decline in $26 \mathrm{~S}$ proteasome activity and slowed polyglutamine-induced neurodegeneration (182). Vilchez and colleagues recently reported that overexpression of the 19S regulatory subunit Rpn6 was sufficient to prolong lifespan and confer resistance to proteotoxic stress in C.elegans (189). Rpn6 has been shown to interact with $\alpha 2$ and Rpt6 subunits, suggesting an important role in stabilising the otherwise weak interaction between $20 \mathrm{~S}$ core particle and $19 \mathrm{~S}$ regulatory particle (147). Consistent with these observations, ectopic expression of Rpn6 was sufficient to increase assembly of $26 \mathrm{~S}$ proteasomes in vivo, with an associated increase in proteasome activity and clearance of polyubiquitinated substrates (189). These findings may have relevance to neurodegenerative disease, since Rpn6-overexpressing worms also displayed enhanced clearance of an aggregated polyQ protein. Taken together, these findings suggest that upregulation of PSMD11, the mammalian homologue of Rpn6, may be a potential strategy to enhance misfolded protein clearance in the context of neurodegenerative disease.

In addition to modulation of regulatory subunit expression levels, recent studies have identified an important role of post-translational modifications in the control of proteasome activity. Phosphorylation of Rpt6 by PKA was sufficient to enhance assembly and activity of the $26 \mathrm{~S}$ proteasome $(7,211)$. Chronic treatment with CGS, an agonist of the $\mathrm{A}_{2 \mathrm{a}}$ adenosine receptor, rescued proteasome activity and facilitated $\mathrm{mtHtt}$ clearance in the striatum of the R6/2 HD mouse model (120). These findings suggest that drugs targeting the $\mathrm{A}_{2 \mathrm{a}}$ receptor and other cAMP-inducing reagents may prove beneficial in the treatment of HD and other neurodegenerative diseases characterised by proteasomal insufficiency. 


\section{Inhibition of polyubiquitin chain-trimming}

Recently, the small molecule inhibitor IU1 was shown to accelerate proteasomal degradation of oxidised and misfolded proteins in cultured cells, including the disease-associated proteins Tau, TDP-43 and Atx3 (115). This enhancement of proteasome activity was shown to be independent of any change in proteasome subunit composition and instead relied on inhibition of ubiquitin chain-trimming by the proteasome-associated DUB Usp14. Chaintrimming by Usp14 is thought to occur in a stepwise manner, disassembling the chain from its distal tip, which may suppress proteolytic activity by promoting substrate dissociation from the proteasome prior to degradation. Thus, inhibition of Usp14 by IU1 may act to stabilise ubiquitinated substrates on the proteasome until they are unfolded and translocated into the 20S core particle for proteolytic clearance. It remains unclear whether IU1 provides resistance to proteotoxic stress in neurons and more importantly, whether it has efficacy in animal models of neurodegenerative disease. 


\section{Conclusion}

Proteostasis network dysfunction due to impairment of the UPS is likely to have pleiotropic effects in the neurodegenerative brain. Whilst distinct pathogenic mechanisms will operate in different neurodegenerative diseases, many common pathways have been proposed which could contribute to progressive neurotoxicity, synaptic dysfunction and ultimately cell death (Fig. 5). Therapeutic strategies to target these downstream neurotoxic sequelae may have limited efficacy due to their late-onset in the course of disease progression. Thus, early intervention to compensate for the accumulation of misfolded proteins by induction of protein catabolism may be an important defensive, or even therapeutic, strategy against these age-related disorders. At first glance, the UPS appears an unlikely target since ubiquitination and proteasomal degradation are involved in the regulation of most cellular protein networks. However, carefully tailored therapies which target CNS-specific components of the UPS may restrict adverse effects. CNS-specific induction of general UPS components such as the 20S or $19 \mathrm{~S}$ complexes could be achieved by the use of viral vectors with neuronal tropism. Alternatively, viral delivery of specific E3 ligases (e.g. parkin, CHIP) which target defined disease-associated proteins could represent customised therapies for the treatment of different neurodegenerative conditions. Whilst considerable progress has been made in the development of viral vector-based therapies for clinical use, significant challenges still remain including the regulation of transgene expression levels and methods for widespread anatomical delivery (198). Due to these technical limitations, the development of synthetic or naturally occurring compounds which upregulate the UPS and are capable of crossing the blood-brain barrier will remain a research priority. The success of any future therapies will depend upon the identification of reliable biomarkers to facilitate early diagnosis and allow intervention before global disruption of the cellular proteome becomes established (143). 


\section{Acknowledgements}

We thank Dr. P. McGoldrick for helpful comments on the manuscript. SJT's lab receives funding from the MRC, BBSRC, EU FP7 Paddington and Neuromics awards, CHDI Foundation, UK HD Association, EHDN seed funds, Dendron and NIHR via the UCL/UCLH BRC. CM is the recipient of an UCLH CBRC studentship.

\section{Author disclosure statement}

No competing financial interests exist. 


\begin{tabular}{|c|c|}
\hline \multicolumn{2}{|r|}{ Abbreviations used } \\
\hline $\mathrm{AD}$ & Alzheimer's disease \\
\hline ALS & Amyotrophic lateral sclerosis \\
\hline Atx3 & ataxin-3 \\
\hline$A \beta$ & $\beta$-amyloid protein \\
\hline CaMKII & $\begin{array}{l}\mathrm{Ca}^{2+} / \text { calmodulin-dependent protein kinase } \\
\text { II }\end{array}$ \\
\hline CHIP & $\begin{array}{l}\text { carboxy terminus of Hsc70-interacting } \\
\text { protein }\end{array}$ \\
\hline CNS & central nervous system \\
\hline DLBD & diffuse Lewy body disease \\
\hline ERAD & ER-associated protein degradation \\
\hline FRAP & fluorescence recovery after photobleaching \\
\hline FUS & Fused in Sarcoma protein \\
\hline HD & Huntington's disease \\
\hline IB & inclusion body \\
\hline IBMPFD & $\begin{array}{l}\text { Inclusion body myopathy with Paget's } \\
\text { disease of bone and frontotemporal } \\
\text { dementia }\end{array}$ \\
\hline IKK & IкB kinase \\
\hline IMM & inner mitochondrial membrane \\
\hline LB & Lewy body \\
\hline LTD & long term depression \\
\hline LTP & long term potentiation \\
\hline MPTP & $\begin{array}{l}\text { 1-methyl-4-phenyl-1,2,3,6- } \\
\text { tetrahydropyridine }\end{array}$ \\
\hline $\mathrm{mtHtt}$ & mutant huntingtin \\
\hline NFT & neurofibrillary tangle \\
\hline OMM & outer mitochondrial membrane \\
\hline PD & Parkinson's disease \\
\hline PHF & paired-helical filament \\
\hline PKA & protein kinase A \\
\hline POMP & proteasome maturation protein \\
\hline PROTAC & proteolysis targeting chimeric molecules \\
\hline $\operatorname{PrP}$ & prion protein \\
\hline $\mathrm{PrPC}$ & normal isoform of the prion protein \\
\hline $\mathrm{PrPSc}$ & disease-associated prion protein \\
\hline Rpt & regulatory particle triple-A \\
\hline Rpn & regulatory particle non-ATPase \\
\hline rAAV & recombinant adeno-associated virus \\
\hline RIM1 & Rab3-interacting molecule 1 \\
\hline ROS & reactive oxygen species \\
\hline SCA3 & Spinocerebellar ataxia type 3 \\
\hline SOD1 & superoxide dismutase 1 \\
\hline SPAR & $\begin{array}{l}\text { spine-associated Rap GTPase activating } \\
\text { protein }\end{array}$ \\
\hline TDP-43 & TAR-DNA binding protein 43 \\
\hline UIM & ubiquitin-interacting motif \\
\hline UPS & ubiquitin-proteasome system \\
\hline $\mathrm{VCP}$ & valosin-containing protein \\
\hline
\end{tabular}




\section{References}

1. Abeliovich A, Schmitz Y, Fariñas I, Choi-Lundberg D, Ho WH, Castillo PE, Shinsky N, Verdugo JM, Armanini M, Ryan A, Hynes M, Phillips H, Sulzer D, Rosenthal A. Mice lacking alpha-synuclein display functional deficits in the nigrostriatal dopamine system. Neuron 25: 239-252, 2000.

2. Abramzon Y, Johnson JO, Scholz SW, Taylor JP, Brunetti M, Calvo A, Mandrioli J, Benatar M, Mora G, Restagno G, Chiò A, Traynor BJ. Valosin-containing protein (VCP) mutations in sporadic amyotrophic lateral sclerosis. Neurobiol. Aging 33: 2231.e1-2231.e6, 2012.

3. Anderson C, Crimmins S, Wilson JA, Korbel GA, Ploegh HL, Wilson SM. Loss of Usp14 results in reduced levels of ubiquitin in ataxia mice. J. Neurochem. 95: 724$731,2005$.

4. Ang XL, Seeburg DP, Sheng M, Harper JW. Regulation of postsynaptic RapGAP SPAR by Polo-like kinase 2 and the SCFbeta-TRCP ubiquitin ligase in hippocampal neurons. J. Biol. Chem. 283: 29424-29432, 2008.

5. Arriagada PV, Growdon JH, Hedley-Whyte ET, Hyman BT. Neurofibrillary tangles but not senile plaques parallel duration and severity of Alzheimer's disease. Neurology 42: 631-631, 1992.

6. Artinian J, McGauran A-MT, De Jaeger X, Mouledous L, Frances B, Roullet P. Protein degradation, as with protein synthesis, is required during not only long-term spatial memory consolidation but also reconsolidation. Eur. J. Neurosci. 27: 30093019, 2008.

7. Asai M, Tsukamoto O, Minamino T, Asanuma H, Fujita M, Asano Y, Takahama H, Sasaki H, Higo S, Asakura M, Takashima S, Hori M, Kitakaze M. PKA rapidly enhances proteasome assembly and activity in in vivo canine hearts. J. Mol. Cell. Cardiol. 46: 452-462, 2009.

8. Ayadi AE, Stieren ES, Barral JM, Boehning D. Ubiquilin-1 regulates amyloid precursor protein maturation and degradation by stimulating K63-linked polyubiquitination of lysine 688. Proc. Natl. Acad. Sci. 109: 13416-13421, 2012.

9. Basso M, Massignan T, Samengo G, Cheroni C, De Biasi S, Salmona M, Bendotti C, Bonetto V. Insoluble mutant SOD1 is partly oligoubiquitinated in amyotrophic lateral sclerosis mice. J. Biol. Chem. 281: 33325-33335, 2006.

10. Bedford L, Hay D, Devoy A, Paine S, Powe DG, Seth R, Gray T, Topham I, Fone K, Rezvani N, Mee M, Soane T, Layfield R, Sheppard PW, Ebendal T, Usoskin D, Lowe $\mathrm{J}$, Mayer RJ. Depletion of $26 \mathrm{~S}$ proteasomes in mouse brain neurons causes neurodegeneration and Lewy-like inclusions resembling human pale bodies. $J$. Neurosci. Off. J. Soc. Neurosci. 28: 8189-8198, 2008.

11. Bedford L, Paine S, Sheppard PW, Mayer RJ, Roelofs J. Assembly, structure, and function of the 26S proteasome. Trends Cell Biol. 20: 391-401, 2010. 
12. Bennett EJ, Shaler TA, Woodman B, Ryu K-Y, Zaitseva TS, Becker CH, Bates GP, Schulman H, Kopito RR. Global changes to the ubiquitin system in Huntington's disease. Nature 448: 704-708, 2007.

13. Bertram L, Hiltunen M, Parkinson M, Ingelsson M, Lange C, Ramasamy K, Mullin K, Menon R, Sampson AJ, Hsiao MY, Elliott KJ, Velicelebi G, Moscarillo T, Hyman BT, Wagner SL, Becker KD, Blacker D, Tanzi RE. Family-Based Association between Alzheimer's Disease and Variants in UBQLN1. N. Engl. J. Med. 352: 884-894, 2005.

14. Besche HC, Haas W, Gygi SP, Goldberg AL. Isolation of mammalian 26S proteasomes and p97/VCP complexes using the ubiquitin-like domain from HHR23B reveals novel proteasome-associated proteins. Biochemistry (Mosc.) 48: 2538-2549, 2009.

15. Bett JS, Goellner GM, Woodman B, Pratt G, Rechsteiner M, Bates GP. Proteasome impairment does not contribute to pathogenesis in R6/2 Huntington's disease mice: exclusion of proteasome activator REGgamma as a therapeutic target. Hum. Mol. Genet. 15: 33-44, 2006.

16. Bhattacharyya BJ, Wilson SM, Jung H, Miller RJ. Altered neurotransmitter release machinery in mice deficient for the deubiquitinating enzyme Usp14. Am. J. Physiol. Cell Physiol. 302: C698-708, 2012.

17. Bingol B, Schuman EM. Activity-dependent dynamics and sequestration of proteasomes in dendritic spines. Nature 441: 1144-1148, 2006.

18. Bingol B, Wang C-F, Arnott D, Cheng D, Peng J, Sheng M. Autophosphorylated CaMKII $\alpha$ Acts as a Scaffold to Recruit Proteasomes to Dendritic Spines. Cell 140: 567-578, 2010.

19. Bosch M, Hayashi Y. Structural plasticity of dendritic spines. Curr. Opin. Neurobiol. 22: 383-388, 2012.

20. Bosco DA, Landers JE. Genetic determinants of amyotrophic lateral sclerosis as therapeutic targets. CNS Neurol. Disord. Drug Targets 9: 779-790, 2010.

21. Bosco DA, LaVoie MJ, Petsko GA, Ringe D. Proteostasis and movement disorders: Parkinson's disease and amyotrophic lateral sclerosis. Cold Spring Harb. Perspect. Biol. 3: a007500, 2011.

22. Bosco DA, Morfini G, Karabacak NM, Song Y, Gros-Louis F, Pasinelli P, Goolsby H, Fontaine BA, Lemay N, McKenna-Yasek D, Frosch MP, Agar JN, Julien J-P, Brady ST, Brown RH Jr. Wild-type and mutant SOD1 share an aberrant conformation and a common pathogenic pathway in ALS. Nat. Neurosci. 13: 1396-1403, 2010.

23. Braak H, Braak E. Demonstration of amyloid deposits and neurofibrillary changes in whole brain sections. Brain Pathol. Zurich Switz. 1: 213-216, 1991.

24. Braak H, Braak E. Staging of Alzheimer's disease-related neurofibrillary changes. Neurobiol. Aging 16: 271-278; discussion 278-284, 1995.

25. Büeler H, Aguzzi A, Sailer A, Greiner RA, Autenried P, Aguet M, Weissmann C. 
Mice devoid of PrP are resistant to scrapie. Cell 73: 1339-1347, 1993.

26. Bulteau AL, Petropoulos I, Friguet B. Age-related alterations of proteasome structure and function in aging epidermis. Exp. Gerontol. 35: 767-777, 2000.

27. Burns MP, Zhang L, Rebeck GW, Querfurth HW, Moussa CE-H. Parkin promotes intracellular Aß1-42 clearance. Hum. Mol. Genet. 18: 3206-3216, 2009.

28. Butterfield DA, Gnjec A, Poon HF, Castegna A, Pierce WM, Klein JB, Martins RN. Redox proteomics identification of oxidatively modified brain proteins in inherited Alzheimer's disease: An initial assessment. J. Alzheimers Dis. 10: 391-397, 2006.

29. Carrard G, Bulteau A-L, Petropoulos I, Friguet B. Impairment of proteasome structure and function in aging. Int. J. Biochem. Cell Biol. 34: 1461-1474, 2002.

30. Cassel JA, Reitz AB. Ubiquilin-2 (UBQLN2) binds with high affinity to the Cterminal region of TDP-43 and modulates TDP-43 levels in H4 cells: Characterization of inhibition by nucleic acids and 4-aminoquinolines. Biochim. Biophys. Acta (March 27, 2013). doi: 10.1016/j.bbapap.2013.03.020.

31. Chan NC, Salazar AM, Pham AH, Sweredoski MJ, Kolawa NJ, Graham RLJ, Hess S, Chan DC. Broad activation of the ubiquitin-proteasome system by Parkin is critical for mitophagy. Hum. Mol. Genet. 20: 1726-1737, 2011.

32. Chen L, Thiruchelvam MJ, Madura K, Richfield EK. Proteasome dysfunction in aged human alpha-synuclein transgenic mice. Neurobiol. Dis. 23: 120-126, 2006.

33. Chen P-C, Bhattacharyya BJ, Hanna J, Minkel H, Wilson JA, Finley D, Miller RJ, Wilson SM. Ubiquitin homeostasis is critical for synaptic development and function. $J$. Neurosci. Off. J. Soc. Neurosci. 31: 17505-17513, 2011.

34. Chen P-C, Qin L-N, Li X-M, Walters BJ, Wilson JA, Mei L, Wilson SM. The proteasome-associated deubiquitinating enzyme Usp14 is essential for the maintenance of synaptic ubiquitin levels and the development of neuromuscular junctions. $J$. Neurosci. Off. J. Soc. Neurosci. 29: 10909-10919, 2009.

35. Cheroni C, Marino M, Tortarolo M, Veglianese P, De Biasi S, Fontana E, Zuccarello LV, Maynard CJ, Dantuma NP, Bendotti C. Functional alterations of the ubiquitinproteasome system in motor neurons of a mouse model of familial amyotrophic lateral sclerosis. Hum. Mol. Genet. 18: 82-96, 2009.

36. Cheroni C, Peviani M, Cascio P, Debiasi S, Monti C, Bendotti C. Accumulation of human SOD1 and ubiquitinated deposits in the spinal cord of SOD1G93A mice during motor neuron disease progression correlates with a decrease of proteasome. Neurobiol. Dis. 18: 509-522, 2005.

37. Choi J, Levey AI, Weintraub ST, Rees HD, Gearing M, Chin L-S, Li L. Oxidative Modifications and Down-regulation of Ubiquitin Carboxyl-terminal Hydrolase L1 Associated with Idiopathic Parkinson's and Alzheimer's Diseases. J. Biol. Chem. 279: 13256-13264, 2004.

38. Chondrogianni N, Gonos ES. Overexpression of hUMP1/POMP proteasome accessory 
protein enhances proteasome-mediated antioxidant defence. Exp. Gerontol. 42: 899903, 2007.

39. Chondrogianni N, Tzavelas C, Pemberton AJ, Nezis IP, Rivett AJ, Gonos ES. Overexpression of proteasome beta5 assembled subunit increases the amount of proteasome and confers ameliorated response to oxidative stress and higher survival rates. J. Biol. Chem. 280: 11840-11850, 2005.

40. Chou AP, Li S, Fitzmaurice AG, Bronstein JM. Mechanisms of rotenone-induced proteasome inhibition. Neurotoxicology 31: 367-372, 2010.

41. Chung KKK, Thomas B, Li X, Pletnikova O, Troncoso JC, Marsh L, Dawson VL, Dawson TM. S-nitrosylation of parkin regulates ubiquitination and compromises parkin's protective function. Science 304: 1328-1331, 2004.

42. Connell P, Ballinger CA, Jiang J, Wu Y, Thompson LJ, Höhfeld J, Patterson C. The co-chaperone CHIP regulates protein triage decisions mediated by heat-shock proteins. Nat. Cell Biol. 3: 93-96, 2001.

43. Cook C, Gendron TF, Scheffel K, Carlomagno Y, Dunmore J, DeTure M, Petrucelli L. Loss of HDAC6, a novel CHIP substrate, alleviates abnormal tau accumulation. Hum. Mol. Genet. 21: 2936-2945, 2012.

44. Cozzolino M, Pesaresi MG, Gerbino V, Grosskreutz J, Carrì MT. Amyotrophic lateral sclerosis: new insights into underlying molecular mechanisms and opportunities for therapeutic intervention. Antioxidants Redox Signal. 17: 1277-1330, 2012.

45. Crippa V, Sau D, Rusmini P, Boncoraglio A, Onesto E, Bolzoni E, Galbiati M, Fontana E, Marino M, Carra S, Bendotti C, De Biasi S, Poletti A. The small heat shock protein B8 (HspB8) promotes autophagic removal of misfolded proteins involved in amyotrophic lateral sclerosis (ALS). Hum. Mol. Genet. 19: 3440-3456, 2010.

46. Dächsel JC, Lücking CB, Deeg S, Schultz E, Lalowski M, Casademunt E, Corti O, Hampe C, Patenge N, Vaupel K, Yamamoto A, Dichgans M, Brice A, Wanker EE, Kahle PJ, Gasser T. Parkin interacts with the proteasome subunit alpha4. FEBS Lett. 579: 3913-3919, 2005.

47. Dahlmann B, Rutschmann M, Kuehn L, Reinauer H. Activation of the multicatalytic proteinase from rat skeletal muscle by fatty acids or sodium dodecyl sulphate. Biochem. J. 228: 171-177, 1985.

48. Dai RM, Li CC. Valosin-containing protein is a multi-ubiquitin chain-targeting factor required in ubiquitin-proteasome degradation. Nat. Cell Biol. 3: 740-744, 2001.

49. Daily JL, Nash K, Jinwal U, Golde T, Rogers J, Peters MM, Burdine RD, Dickey C, Banko JL, Weeber EJ. Adeno-associated virus-mediated rescue of the cognitive defects in a mouse model for Angelman syndrome. PloS One 6: e27221, 2011.

50. Dalal S, Rosser MFN, Cyr DM, Hanson PI. Distinct Roles for the AAA ATPases NSF and p97 in the Secretory Pathway. Mol. Biol. Cell 15: 637-648, 2004.

51. Daoud H, Suhail H, Szuto A, Camu W, Salachas F, Meininger V, Bouchard J-P, Dupré 
N, Dion PA, Rouleau GA. UBQLN2 mutations are rare in French and FrenchCanadian amyotrophic lateral sclerosis. Neurobiol. Aging 33: 2230.e1-2230.e5, 2012.

52. Deng H-X, Chen W, Hong S-T, Boycott KM, Gorrie GH, Siddique N, Yang Y, Fecto F, Shi Y, Zhai H, Jiang H, Hirano M, Rampersaud E, Jansen GH, Donkervoort S, Bigio EH, Brooks BR, Ajroud K, Sufit RL, Haines JL, Mugnaini E, Pericak-Vance MA, Siddique T. Mutations in UBQLN2 cause dominant X-linked juvenile and adultonset ALS and ALS/dementia. Nature 477: 211-215, 2011.

53. Deriziotis P, André R, Smith DM, Goold R, Kinghorn KJ, Kristiansen M, Nathan JA, Rosenzweig R, Krutauz D, Glickman MH, Collinge J, Goldberg AL, Tabrizi SJ. Misfolded PrP impairs the UPS by interaction with the 20S proteasome and inhibition of substrate entry. EMBO J. 30: 3065-3077, 2011.

54. Díaz-Hernández M, Hernández F, Martín-Aparicio E, Gómez-Ramos P, Morán MA, Castaño JG, Ferrer I, Avila J, Lucas JJ. Neuronal induction of the immunoproteasome in Huntington's disease. J. Neurosci. Off. J. Soc. Neurosci. 23: 11653-11661, 2003.

55. Dick TP, Nussbaum AK, Deeg M, Heinemeyer W, Groll M, Schirle M, Keilholz W, Stevanović S, Wolf DH, Huber R, Rammensee HG, Schild H. Contribution of proteasomal beta-subunits to the cleavage of peptide substrates analyzed with yeast mutants. J. Biol. Chem. 273: 25637-25646, 1998.

56. Dickey CA, Yue M, Lin W-L, Dickson DW, Dunmore JH, Lee WC, Zehr C, West G, Cao S, Clark AMK, Caldwell GA, Caldwell KA, Eckman C, Patterson C, Hutton M, Petrucelli L. Deletion of the ubiquitin ligase CHIP leads to the accumulation, but not the aggregation, of both endogenous phospho- and caspase-3-cleaved tau species. $J$. Neurosci. Off. J. Soc. Neurosci. 26: 6985-6996, 2006.

57. Djakovic SN, Schwarz LA, Barylko B, DeMartino GN, Patrick GN. Regulation of the proteasome by neuronal activity and calcium/calmodulin-dependent protein kinase II. J. Biol. Chem. 284: 26655-26665, 2009.

58. Drews O, Wildgruber R, Zong C, Sukop U, Nissum M, Weber G, Gomes AV, Ping P. Mammalian proteasome subpopulations with distinct molecular compositions and proteolytic activities. Mol. Cell. Proteomics MCP 6: 2021-2031, 2007.

59. Dringen R. Metabolism and functions of glutathione in brain. Prog. Neurobiol. 62: 649-671, 2000.

60. Dyllick-Brenzinger M, D’Souza CA, Dahlmann B, Kloetzel P-M, Tandon A. Reciprocal effects of alpha-synuclein overexpression and proteasome inhibition in neuronal cells and tissue. Neurotox. Res. 17: 215-227, 2010.

61. Ebrahimi-Fakhari D, Cantuti-Castelvetri I, Fan Z, Rockenstein E, Masliah E, Hyman BT, McLean PJ, Unni VK. Distinct roles in vivo for the ubiquitin-proteasome system and the autophagy-lysosomal pathway in the degradation of $\alpha$-synuclein. J. Neurosci. Off. J. Soc. Neurosci. 31: 14508-14520, 2011.

62. Emmanouilidou E, Stefanis L, Vekrellis K. Cell-produced alpha-synuclein oligomers are targeted to, and impair, the 26S proteasome. Neurobiol. Aging 31: 953-968, 2010. 
63. Fischer DF, van Dijk R, van Tijn P, Hobo B, Verhage MC, van der Schors RC, Wan Li $\mathrm{K}$, van Minnen J, Hol EM, van Leeuwen FW. Long-term proteasome dysfunction in the mouse brain by expression of aberrant ubiquitin. Neurobiol. Aging 30: 847-863, 2009.

64. Fornai F, Schlüter OM, Lenzi P, Gesi M, Ruffoli R, Ferrucci M, Lazzeri G, Busceti CL, Pontarelli F, Battaglia G, Pellegrini A, Nicoletti F, Ruggieri S, Paparelli A, Südhof TC. Parkinson-like syndrome induced by continuous MPTP infusion: convergent roles of the ubiquitin-proteasome system and alpha-synuclein. Proc. Natl. Acad. Sci. U. S. A. 102: 3413-3418, 2005.

65. Forsberg K, Jonsson PA, Andersen PM, Bergemalm D, Graffmo KS, Hultdin M, Jacobsson J, Rosquist R, Marklund SL, Brännström T. Novel antibodies reveal inclusions containing non-native SOD1 in sporadic ALS patients. PloS One 5: e11552, 2010 .

66. Friguet B. Oxidized protein degradation and repair in ageing and oxidative stress. FEBS Lett. 580: 2910-2916, 2006.

67. Gaczynska M, Goldberg AL, Tanaka K, Hendil KB, Rock KL. Proteasome subunits X and $\mathrm{Y}$ alter peptidase activities in opposite ways to the interferon-gamma-induced subunits LMP2 and LMP7. J. Biol. Chem. 271: 17275-17280, 1996.

68. Gaczynska M, Rock KL, Spies T, Goldberg AL. Peptidase activities of proteasomes are differentially regulated by the major histocompatibility complex-encoded genes for LMP2 and LMP7. Proc. Natl. Acad. Sci. U. S. A. 91: 9213-9217, 1994.

69. Gitcho MA, Strider J, Carter D, Taylor-Reinwald L, Forman MS, Goate AM, Cairns NJ. VCP mutations causing frontotemporal lobar degeneration disrupt localization of TDP-43 and induce cell death. J. Biol. Chem. 284: 12384-12398, 2009.

70. Glickman $\mathrm{MH}$, Ciechanover A. The ubiquitin-proteasome proteolytic pathway: destruction for the sake of construction. Physiol. Rev. 82: 373-428, 2002.

71. Glickman MH, Raveh D. Proteasome plasticity. FEBS Lett. 579: 3214-3223, 2005.

72. Gong B, Cao Z, Zheng P, Vitolo OV, Liu S, Staniszewski A, Moolman D, Zhang H, Shelanski M, Arancio O. Ubiquitin Hydrolase Uch-L1 Rescues $\beta$-Amyloid-Induced Decreases in Synaptic Function and Contextual Memory. Cell 126: 775-788, 2006.

73. Greer PL, Hanayama R, Bloodgood BL, Mardinly AR, Lipton DM, Flavell SW, Kim T-K, Griffith EC, Waldon Z, Maehr R, Ploegh HL, Chowdhury S, Worley PF, Steen J, Greenberg ME. The Angelman Syndrome protein Ube3A regulates synapse development by ubiquitinating arc. Cell 140: 704-716, 2010.

74. Grimm S, Höhn A, Grune T. Oxidative protein damage and the proteasome. Amino Acids 42: 23-38, 2012.

75. Groll M, Bajorek M, Köhler A, Moroder L, Rubin DM, Huber R, Glickman MH, Finley D. A gated channel into the proteasome core particle. Nat. Struct. Biol. 7: 10621067, 2000. 
76. Grune T, Botzen D, Engels M, Voss P, Kaiser B, Jung T, Grimm S, Ermak G, Davies KJA. Tau protein degradation is catalyzed by the ATP/ubiquitin-independent $20 \mathrm{~S}$ proteasome under normal cell conditions. Arch. Biochem. Biophys. 500: 181-188, 2010 .

77. Hallengren J, Chen P-C, Wilson SM. Neuronal Ubiquitin Homeostasis. Cell Biochem. Biophys. (May 18, 2013). doi: 10.1007/s12013-013-9634-4.

78. Hamilton AM, Oh WC, Vega-Ramirez H, Stein IS, Hell JW, Patrick GN, Zito K. Activity-Dependent Growth of New Dendritic Spines Is Regulated by the Proteasome. Neuron 74: 1023-1030, 2012.

79. Hartl FU, Bracher A, Hayer-Hartl M. Molecular chaperones in protein folding and proteostasis. Nature 475: 324-332, 2011.

80. Hershko A. Ubiquitin: roles in protein modification and breakdown. Cell 34: 11-12, 1983.

81. Hipp MS, Patel CN, Bersuker K, Riley BE, Kaiser SE, Shaler TA, Brandeis M, Kopito RR. Indirect inhibition of $26 \mathrm{~S}$ proteasome activity in a cellular model of Huntington's disease. J. Cell Biol. 196: 573-587, 2012.

82. Hochstrasser M. Ubiquitin, proteasomes, and the regulation of intracellular protein degradation. Curr. Opin. Cell Biol. 7: 215-223, 1995.

83. Holmberg CI, Staniszewski KE, Mensah KN, Matouschek A, Morimoto RI. Inefficient degradation of truncated polyglutamine proteins by the proteasome. EMBO J. 23: 4307-4318, 2004.

84. Houlden H, Singleton AB. The genetics and neuropathology of Parkinson's disease. Acta Neuropathol. (Berl.) 124: 325-338, 2012.

85. Hung AY, Sung CC, Brito IL, Sheng M. Degradation of postsynaptic scaffold GKAP and regulation of dendritic spine morphology by the TRIM3 ubiquitin ligase in rat hippocampal neurons. PloS One 5: e9842, 2010.

86. Hwang JS, Hwang JS, Chang I, Kim S. Age-associated decrease in proteasome content and activities in human dermal fibroblasts: restoration of normal level of proteasome subunits reduces aging markers in fibroblasts from elderly persons. J. Gerontol. A. Biol. Sci. Med. Sci. 62: 490-499, 2007.

87. Hyun D-H, Lee M, Hattori N, Kubo S-I, Mizuno Y, Halliwell B, Jenner P. Effect of wild-type or mutant Parkin on oxidative damage, nitric oxide, antioxidant defenses, and the proteasome. J. Biol. Chem. 277: 28572-28577, 2002.

88. Ihara Y, Morishima-Kawashima M, Nixon R. The Ubiquitin-Proteasome System and the Autophagic-Lysosomal System in Alzheimer Disease. Cold Spring Harb. Perspect. Med. 2, 2012.

89. Ihara Y, Nukina N, Miura R, Ogawara M. Phosphorylated tau protein is integrated into paired helical filaments in Alzheimer's disease. J. Biochem. (Tokyo) 99: 1807-1810, 1986. 
90. Ironside JW, Ritchie DL, Head MW. Phenotypic variability in human prion diseases. Neuropathol. Appl. Neurobiol. 31: 565-579, 2005.

91. Jana NR, Dikshit P, Goswami A, Kotliarova S, Murata S, Tanaka K, Nukina N. Cochaperone CHIP associates with expanded polyglutamine protein and promotes their degradation by proteasomes. J. Biol. Chem. 280: 11635-11640, 2005.

92. Jana NR, Zemskov EA, Wang Gh, Nukina N. Altered proteasomal function due to the expression of polyglutamine-expanded truncated $\mathrm{N}$-terminal huntingtin induces apoptosis by caspase activation through mitochondrial cytochrome c release. Hum. Mol. Genet. 10: 1049-1059, 2001.

93. Jentsch S, Rumpf S. Cdc48 (p97): a "molecular gearbox" in the ubiquitin pathway? Trends Biochem. Sci. 32: 6-11, 2007.

94. Johnson JO, Mandrioli J, Benatar M, Abramzon Y, Van Deerlin VM, Trojanowski JQ, Gibbs JR, Brunetti M, Gronka S, Wuu J, Ding J, McCluskey L, Martinez-Lage M, Falcone D, Hernandez DG, Arepalli S, Chong S, Schymick JC, Rothstein J, Landi F, Wang Y-D, Calvo A, Mora G, Sabatelli M, Monsurrò MR, Battistini S, Salvi F, Spataro R, Sola P, Borghero G, ITALSGEN Consortium, Galassi G, Scholz SW, Taylor JP, Restagno G, Chiò A, Traynor BJ. Exome sequencing reveals VCP mutations as a cause of familial ALS. Neuron 68: 857-864, 2010.

95. Ju J-S, Fuentealba RA, Miller SE, Jackson E, Piwnica-Worms D, Baloh RH, Weihl CC. Valosin-containing protein (VCP) is required for autophagy and is disrupted in VCP disease. J. Cell Biol. 187: 875-888, 2009.

96. Kabashi E, Agar JN, Hong Y, Taylor DM, Minotti S, Figlewicz DA, Durham HD. Proteasomes remain intact, but show early focal alteration in their composition in a mouse model of amyotrophic lateral sclerosis. J. Neurochem. 105: 2353-2366, 2008.

97. Kabashi E, Agar JN, Strong MJ, Durham HD. Impaired proteasome function in sporadic amyotrophic lateral sclerosis. Amyotroph. Lateral Scler. Off. Publ. World Fed. Neurol. Res. Group Mot. Neuron Dis. 13: 367-371, 2012.

98. Kabashi E, Agar JN, Taylor DM, Minotti S, Durham HD. Focal dysfunction of the proteasome: a pathogenic factor in a mouse model of amyotrophic lateral sclerosis. $J$. Neurochem. 89: 1325-1335, 2004.

99. Kabuta T, Furuta A, Aoki S, Furuta K, Wada K. Aberrant interaction between Parkinson disease-associated mutant UCH-L1 and the lysosomal receptor for chaperone-mediated autophagy. J. Biol. Chem. 283: 23731-23738, 2008.

100. Kabuta T, Setsuie R, Mitsui T, Kinugawa A, Sakurai M, Aoki S, Uchida K, Wada K. Aberrant molecular properties shared by familial Parkinson's disease-associated mutant UCH-L1 and carbonyl-modified UCH-L1. Hum. Mol. Genet. 17: 1482-1496, 2008.

101. Kaiser SE, Riley BE, Shaler TA, Trevino RS, Becker CH, Schulman H, Kopito RR. Protein standard absolute quantification (PSAQ) method for the measurement of cellular ubiquitin pools. Nat. Methods 8: 691-696, 2011. 
102. Kamboh MI, Minster RL, Feingold E, DeKosky ST. Genetic association of ubiquilin with Alzheimer's disease and related quantitative measures. Mol. Psychiatry 11: 273279, 2006.

103. Kang S-C, Brown DR, Whiteman M, Li R, Pan T, Perry G, Wisniewski T, Sy M-S, Wong B-S. Prion protein is ubiquitinated after developing protease resistance in the brains of scrapie-infected mice. J. Pathol. 203: 603-608, 2004.

104. Katsiki M, Chondrogianni N, Chinou I, Rivett AJ, Gonos ES. The olive constituent oleuropein exhibits proteasome stimulatory properties in vitro and confers life span extension of human embryonic fibroblasts. Rejuvenation Res. 10: 157-172, 2007.

105. Keck S, Nitsch R, Grune T, Ullrich O. Proteasome inhibition by paired helical filament-tau in brains of patients with Alzheimer's disease. J. Neurochem. 85: 115$122,2003$.

106. Keller JN, Hanni KB, Markesbery WR. Impaired Proteasome Function in Alzheimer's Disease. J. Neurochem. 75: 436-439, 2000.

107. Kim NC, Tresse E, Kolaitis R-M, Molliex A, Thomas RE, Alami NH, Wang B, Joshi A, Smith RB, Ritson GP, Winborn BJ, Moore J, Lee J-Y, Yao T-P, Pallanck L, Kundu M, Taylor JP. VCP Is Essential for Mitochondrial Quality Control by PINK1/Parkin and this Function Is Impaired by VCP Mutations. Neuron 78: 65-80, 2013.

108. Kishino T, Lalande M, Wagstaff J. UBE3A/E6-AP mutations cause Angelman syndrome. Nat. Genet. 15: 70-73, 1997.

109. Kitada T, Asakawa S, Hattori N, Matsumine H, Yamamura Y, Minoshima S, Yokochi M, Mizuno Y, Shimizu N. Mutations in the parkin gene cause autosomal recessive juvenile parkinsonism. Nature 392: 605-608, 1998.

110. Ko HS, Bailey R, Smith WW, Liu Z, Shin J-H, Lee Y-I, Zhang Y-J, Jiang H, Ross CA, Moore DJ, Patterson C, Petrucelli L, Dawson TM, Dawson VL. CHIP regulates leucine-rich repeat kinase-2 ubiquitination, degradation, and toxicity. Proc. Natl. Acad. Sci. U. S. A. 106: 2897-2902, 2009.

111. Ko HS, Uehara T, Tsuruma K, Nomura Y. Ubiquilin interacts with ubiquitylated proteins and proteasome through its ubiquitin-associated and ubiquitin-like domains. FEBS Lett. 566: 110-114, 2004.

112. Korolchuk VI, Menzies FM, Rubinsztein DC. Mechanisms of cross-talk between the ubiquitin-proteasome and autophagy-lysosome systems. FEBS Lett. 584: 1393-1398, 2010 .

113. Kristiansen M, Deriziotis P, Dimcheff DE, Jackson GS, Ovaa H, Naumann H, Clarke AR, van Leeuwen FWB, Menéndez-Benito V, Dantuma NP, Portis JL, Collinge J, Tabrizi SJ. Disease-associated prion protein oligomers inhibit the $26 \mathrm{~S}$ proteasome. Mol. Cell 26: 175-188, 2007.

114. Lam YA, Pickart CM, Alban A, Landon M, Jamieson C, Ramage R, Mayer RJ, Layfield R. Inhibition of the ubiquitin-proteasome system in Alzheimer's disease. Proc. Natl. Acad. Sci. U. S. A. 97: 9902-9906, 2000. 
115. Lee B-H, Lee MJ, Park S, Oh D-C, Elsasser S, Chen P-C, Gartner C, Dimova N, Hanna J, Gygi SP, Wilson SM, King RW, Finley D. Enhancement of proteasome activity by a small-molecule inhibitor of USP14. Nature 467: 179-184, 2010.

116. Lee S-H, Choi J-H, Lee N, Lee H-R, Kim J-I, Yu N-K, Choi S-L, Lee S-H, Kim H, Kaang B-K. Synaptic protein degradation underlies destabilization of retrieved fear memory. Science 319: 1253-1256, 2008.

117. Van Leeuwen FW, Hol EM, Fischer DF. Frameshift proteins in Alzheimer's disease and in other conformational disorders: Time for the ubiquitin-proteasome system. $J$. Alzheimers Dis. 9: 319-325, 2006.

118. Van Leeuwen FW, de Kleijn DP, van den Hurk HH, Neubauer A, Sonnemans MA, Sluijs JA, Köycü S, Ramdjielal RD, Salehi A, Martens GJ, Grosveld FG, Peter J, Burbach H, Hol EM. Frameshift mutants of beta amyloid precursor protein and ubiquitin-B in Alzheimer's and Down patients. Science 279: 242-247, 1998.

119. Leroy E, Boyer R, Auburger G, Leube B, Ulm G, Mezey E, Harta G, Brownstein MJ, Jonnalagada S, Chernova T, Dehejia A, Lavedan C, Gasser T, Steinbach PJ, Wilkinson KD, Polymeropoulos MH. The ubiquitin pathway in Parkinson's disease. Nature 395: 451-452, 1998.

120. Lin Y-S, Cheng T-H, Chang C-P, Chen H-M, Chern Y. Enhancement of brain-type creatine kinase activity ameliorates neuronal deficits in Huntington's disease. Biochim. Biophys. Acta BBA - Mol. Basis Dis. 1832: 742-753, 2013.

121. Lindersson E, Beedholm R, Højrup P, Moos T, Gai W, Hendil KB, Jensen PH. Proteasomal inhibition by alpha-synuclein filaments and oligomers. J. Biol. Chem. 279: 12924-12934, 2004.

122. Liu Y, Liu X, Zhang T, Luna C, Liton PB, Gonzalez P. Cytoprotective effects of proteasome beta5 subunit overexpression in lens epithelial cells. Mol. Vis. 13: 31-38, 2007.

123. López Salon M, Morelli L, Castaño EM, Soto EF, Pasquini JM. Defective ubiquitination of cerebral proteins in Alzheimer's disease. J. Neurosci. Res. 62: 302$310,2000$.

124. Lopez-Salon M, Alonso M, Vianna MR, Viola H, Mello e Souza T, Izquierdo I, Pasquini JM, Medina JH. The ubiquitin-proteasome cascade is required for mammalian long-term memory formation. Eur. J. Neurosci. 14: 1820-1826, 2001.

125. Maciel P, Costa MC, Ferro A, Rousseau M, Santos CS, Gaspar C, Barros J, Rouleau GA, Coutinho P, Sequeiros J. Improvement in the molecular diagnosis of MachadoJoseph disease. Arch. Neurol. 58: 1821-1827, 2001.

126. Magrané J, Manfredi G. Mitochondrial function, morphology, and axonal transport in amyotrophic lateral sclerosis. Antioxidants Redox Signal. 11: 1615-1626, 2009.

127. Maheshwari M, Samanta A, Godavarthi SK, Mukherjee R, Jana NR. Dysfunction of the Ubiquitin Ligase Ube3a May Be Associated with Synaptic Pathophysiology in a Mouse Model of Huntington Disease. J. Biol. Chem. 287: 29949-29957, 2012. 
128. Maraganore DM, Farrer MJ, Hardy JA, Lincoln SJ, McDonnell SK, Rocca WA. Casecontrol study of the ubiquitin carboxy-terminal hydrolase L1 gene in Parkinson's disease. Neurology 53: 1858-1860, 1999.

129. Mata IF, Wedemeyer WJ, Farrer MJ, Taylor JP, Gallo KA. LRRK2 in Parkinson's disease: protein domains and functional insights. Trends Neurosci. 29: 286-293, 2006.

130. Matos CA, de Macedo-Ribeiro S, Carvalho AL. Polyglutamine diseases: The special case of ataxin-3 and Machado-Joseph disease. Prog. Neurobiol. 95: 26-48, 2011.

131. Matsuura T, Sutcliffe JS, Fang P, Galjaard RJ, Jiang YH, Benton CS, Rommens JM, Beaudet AL. De novo truncating mutations in E6-AP ubiquitin-protein ligase gene (UBE3A) in Angelman syndrome. Nat. Genet. 15: 74-77, 1997.

132. Mattson MP, Magnus T. Ageing and neuronal vulnerability. Nat. Rev. Neurosci. 7: 278-294, 2006.

133. Maynard CJ, Böttcher C, Ortega Z, Smith R, Florea BI, Díaz-Hernández M, Brundin P, Overkleeft HS, Li J-Y, Lucas JJ, Dantuma NP. Accumulation of ubiquitin conjugates in a polyglutamine disease model occurs without global ubiquitin/proteasome system impairment. Proc. Natl. Acad. Sci. 106: 13986-13991, 2009.

134. McNaught KS., Belizaire R, Jenner P, Olanow CW, Isacson O. Selective loss of 20S proteasome $\alpha$-subunits in the substantia nigra pars compacta in Parkinson's disease. Neurosci. Lett. 326: 155-158, 2002.

135. McNaught KS., Jenner P. Proteasomal function is impaired in substantia nigra in Parkinson's disease. Neurosci. Lett. 297: 191-194, 2001.

136. Miller VM, Nelson RF, Gouvion CM, Williams A, Rodriguez-Lebron E, Harper SQ, Davidson BL, Rebagliati MR, Paulson HL. CHIP suppresses polyglutamine aggregation and toxicity in vitro and in vivo. J. Neurosci. Off. J. Soc. Neurosci. 25: 9152-9161, 2005.

137. Mishra A, Maheshwari M, Chhangani D, Fujimori-Tonou N, Endo F, Joshi AP, Jana NR, Yamanaka K. E6-AP association promotes SOD1 aggresomes degradation and suppresses toxicity. Neurobiol. Aging 34: 1310.e11-23, 2013.

138. Mochizuki H. Parkin gene therapy. Parkinsonism Relat. Disord. 15 Suppl 1: S43-45, 2009.

139. Mulherkar SA, Sharma J, Jana NR. The ubiquitin ligase E6-AP promotes degradation of alpha-synuclein. J. Neurochem. 110: 1955-1964, 2009.

140. Nixon RA. The role of autophagy in neurodegenerative disease. Nat. Med. 19: 983997, 2013.

141. Oddo S, Caccamo A, Shepherd JD, Murphy MP, Golde TE, Kayed R, Metherate R, Mattson MP, Akbari Y, LaFerla FM. Triple-Transgenic Model of Alzheimer's Disease with Plaques and Tangles: Intracellular $A \beta$ and Synaptic Dysfunction. Neuron 39: 409-421, 2003. 
142. Oddo S, Caccamo A, Tseng B, Cheng D, Vasilevko V, Cribbs DH, LaFerla FM. Blocking A $\beta 42$ Accumulation Delays the Onset and Progression of Tau Pathology via the C Terminus of Heat Shock Protein70-Interacting Protein: A Mechanistic Link between A $\beta$ and Tau Pathology. J. Neurosci. 28: 12163-12175, 2008.

143. Olzscha H, Schermann SM, Woerner AC, Pinkert S, Hecht MH, Tartaglia GG, Vendruscolo M, Hayer-Hartl M, Hartl FU, Vabulas RM. Amyloid-like aggregates sequester numerous metastable proteins with essential cellular functions. Cell 144: 67$78,2011$.

144. Orr AL, Li S, Wang C-E, Li H, Wang J, Rong J, Xu X, Mastroberardino PG, Greenamyre JT, Li X-J. N-terminal mutant huntingtin associates with mitochondria and impairs mitochondrial trafficking. J. Neurosci. Off. J. Soc. Neurosci. 28: 27832792, 2008.

145. Ortega Z, Díaz-Hernández M, Maynard CJ, Hernández F, Dantuma NP, Lucas JJ. Acute Polyglutamine Expression in Inducible Mouse Model Unravels Ubiquitin/Proteasome System Impairment and Permanent Recovery Attributable to Aggregate Formation. J. Neurosci. 30: 3675-3688, 2010.

146. Osaka H, Wang Y-L, Takada K, Takizawa S, Setsuie R, Li H, Sato Y, Nishikawa K, Sun Y-J, Sakurai M, Harada T, Hara Y, Kimura I, Chiba S, Namikawa K, Kiyama H, Noda M, Aoki S, Wada K. Ubiquitin carboxy-terminal hydrolase L1 binds to and stabilizes monoubiquitin in neuron. Hum. Mol. Genet. 12: 1945-1958, 2003.

147. Pathare GR, Nagy I, Bohn S, Unverdorben P, Hubert A, Körner R, Nickell S, Lasker K, Sali A, Tamura T, Nishioka T, Förster F, Baumeister W, Bracher A. The proteasomal subunit Rpn6 is a molecular clamp holding the core and regulatory subcomplexes together. Proc. Natl. Acad. Sci. 109: 149-154, 2012.

148. Peth A, Besche HC, Goldberg AL. Ubiquitinated proteins activate the proteasome by binding to Usp14/Ubp6, which causes 20S gate opening. Mol. Cell 36: 794-804, 2009.

149. Peth A, Kukushkin N, Bossé M, Goldberg AL. Ubiquitinated proteins activate the proteasomal ATPases by binding to Usp14 or Uch37 homologs. J. Biol. Chem. 288: 7781-7790, 2013.

150. Petropoulos I, Conconi M, Wang X, Hoenel B, Brégégère F, Milner Y, Friguet B. Increase of oxidatively modified protein is associated with a decrease of proteasome activity and content in aging epidermal cells. J. Gerontol. A. Biol. Sci. Med. Sci. 55: B220-227, 2000.

151. Petrucelli L, Dickson D, Kehoe K, Taylor J, Snyder H, Grover A, De Lucia M, McGowan E, Lewis J, Prihar G, Kim J, Dillmann WH, Browne SE, Hall A, Voellmy R, Tsuboi Y, Dawson TM, Wolozin B, Hardy J, Hutton M. CHIP and Hsp70 regulate tau ubiquitination, degradation and aggregation. Hum. Mol. Genet. 13: 703-714, 2004.

152. Prabhudesai S, Sinha S, Attar A, Kotagiri A, Fitzmaurice AG, Lakshmanan R, Lakshmanan R, Ivanova MI, Loo JA, Klärner F-G, Schrader T, Stahl M, Bitan G, Bronstein JM. A novel "molecular tweezer" inhibitor of $\alpha$-synuclein neurotoxicity in vitro and in vivo. Neurother. J. Am. Soc. Exp. Neurother. 9: 464-476, 2012. 
153. Prusiner SB. Novel proteinaceous infectious particles cause scrapie. Science 216: 136144, 1982.

154. Quaglio E, Restelli E, Garofoli A, Dossena S, De Luigi A, Tagliavacca L, Imperiale D, Migheli A, Salmona M, Sitia R, Forloni G, Chiesa R. Expression of mutant or cytosolic PrP in transgenic mice and cells is not associated with endoplasmic reticulum stress or proteasome dysfunction. PloS One 6: e19339, 2011.

155. Rodriguez-Gonzalez A, Cyrus K, Salcius M, Kim K, Crews CM, Deshaies RJ, Sakamoto KM. Targeting steroid hormone receptors for ubiquitination and degradation in breast and prostate cancer. Oncogene 27: 7201-7211, 2008.

156. Rosen KM, Moussa CE-H, Lee H-K, Kumar P, Kitada T, Qin G, Fu Q, Querfurth HW. Parkin reverses intracellular $\beta$-amyloid accumulation and its negative effects on proteasome function. J. Neurosci. Res. 88: 167-178, 2010.

157. Ross CA, Tabrizi SJ. Huntington's disease: from molecular pathogenesis to clinical treatment. Lancet Neurol. 10: 83-98, 2011.

158. Rott R, Szargel R, Haskin J, Bandopadhyay R, Lees AJ, Shani V, Engelender S. $\alpha$ Synuclein fate is determined by USP9X-regulated monoubiquitination. Proc. Natl. Acad. Sci. U. S. A. 108: 18666-18671, 2011.

159. Ryu K-Y, Garza JC, Lu X-Y, Barsh GS, Kopito RR. Hypothalamic neurodegeneration and adult-onset obesity in mice lacking the Ubb polyubiquitin gene. Proc. Natl. Acad. Sci. U. S. A. 105: 4016-4021, 2008.

160. Sau D, De Biasi S, Vitellaro-Zuccarello L, Riso P, Guarnieri S, Porrini M, Simeoni S, Crippa V, Onesto E, Palazzolo I, Rusmini P, Bolzoni E, Bendotti C, Poletti A. Mutation of SOD1 in ALS: a gain of a loss of function. Hum. Mol. Genet. 16: 16041618, 2007.

161. Schellenberg GD, Montine TJ. The genetics and neuropathology of Alzheimer's disease. Acta Neuropathol. (Berl.) 124: 305-323, 2012.

162. Schneekloth AR, Pucheault M, Tae HS, Crews CM. Targeted intracellular protein degradation induced by a small molecule: En route to chemical proteomics. Bioorg. Med. Chem. Lett. 18: 5904-5908, 2008.

163. Seeburg DP, Feliu-Mojer M, Gaiottino J, Pak DTS, Sheng M. Critical role of CDK5 and Polo-like kinase 2 in homeostatic synaptic plasticity during elevated activity. Neuron 58: 571-583, 2008.

164. Selkoe DJ. Alzheimer's disease results from the cerebral accumulation and cytotoxicity of amyloid beta-protein. J. Alzheimers Dis. JAD 3: 75-80, 2001.

165. Seo H, Sonntag K-C, Isacson O. Generalized brain and skin proteasome inhibition in Huntington's disease. Ann. Neurol. 56: 319-328, 2004.

166. Shamoto-Nagai M, Maruyama W, Kato Y, Isobe K, Tanaka M, Naoi M, Osawa T. An inhibitor of mitochondrial complex I, rotenone, inactivates proteasome by oxidative modification and induces aggregation of oxidized proteins in SH-SY5Y cells. J. 
Neurosci. Res. 74: 589-597, 2003.

167. Shimura H, Schwartz D, Gygi SP, Kosik KS. CHIP-Hsc70 complex ubiquitinates phosphorylated tau and enhances cell survival. J. Biol. Chem. 279: 4869-4876, 2004.

168. Shin Y, Klucken J, Patterson C, Hyman BT, McLean PJ. The co-chaperone carboxyl terminus of Hsp70-interacting protein (CHIP) mediates alpha-synuclein degradation decisions between proteasomal and lysosomal pathways. J. Biol. Chem. 280: 2372723734, 2005.

169. Slifer MA, Martin ER, Bronson PG, Browning-Large C, Doraiswamy PM, WelshBohmer KA, Gilbert JR, Haines JL, Pericak-Vance MA. Lack of association between UBQLN1 and Alzheimer disease. Am. J. Med. Genet. Part B Neuropsychiatr. Genet. Off. Publ. Int. Soc. Psychiatr. Genet. 141B: 208-213, 2006.

170. Snyder H, Mensah K, Theisler C, Lee J, Matouschek A, Wolozin B. Aggregated and monomeric alpha-synuclein bind to the S6' proteasomal protein and inhibit proteasomal function. J. Biol. Chem. 278: 11753-11759, 2003.

171. Spina S, Van Laar AD, Murrell JR, Hamilton RL, Kofler JK, Epperson F, Farlow MR, Lopez OL, Quinlan J, DeKosky ST, Ghetti B. Phenotypic variability in three families with valosin-containing protein mutation. Eur. J. Neurol. Off. J. Eur. Fed. Neurol. Soc. 20: 251-258, 2013.

172. Stieren ES, El Ayadi A, Xiao Y, Siller E, Landsverk ML, Oberhauser AF, Barral JM, Boehning D. Ubiquilin-1 is a molecular chaperone for the amyloid precursor protein. $J$. Biol. Chem. 286: 35689-35698, 2011.

173. Suraweera A, Münch C, Hanssum A, Bertolotti A. Failure of Amino Acid Homeostasis Causes Cell Death following Proteasome Inhibition. Mol. Cell 48: 242-253, 2012.

174. Tai H-C, Besche H, Goldberg AL, Schuman EM. Characterization of the brain 26S proteasome and its interacting proteins. Front. Mol. Neurosci. 3: 12, 2010.

175. Tan Z, Sun X, Hou F-S, Oh H-W, Hilgenberg LGW, Hol EM, van Leeuwen FW, Smith MA, O'Dowd DK, Schreiber SS. Mutant ubiquitin found in Alzheimer's disease causes neuritic beading of mitochondria in association with neuronal degeneration. Cell Death Differ. 14: 1721-1732, 2007.

176. Tanaka A, Cleland MM, Xu S, Narendra DP, Suen D-F, Karbowski M, Youle RJ. Proteasome and p97 mediate mitophagy and degradation of mitofusins induced by Parkin. J. Cell Biol. 191: 1367-1380, 2010.

177. Tanaka S, Saito M, Morimatsu M, Ohama E. Immunohistochemical studies of the PrP(CJD) deposition in Creutzfeldt-Jakob disease. Neuropathol. Off. J. Jpn. Soc. Neuropathol. 20: 124-133, 2000.

178. Tashiro Y, Urushitani M, Inoue H, Koike M, Uchiyama Y, Komatsu M, Tanaka K, Yamazaki M, Abe M, Misawa H, Sakimura K, Ito H, Takahashi R. Motor neuronspecific disruption of proteasomes, but not autophagy, replicates amyotrophic lateral sclerosis. J. Biol. Chem. 287: 42984-42994, 2012. 
179. Tetzlaff JE, Putcha P, Outeiro TF, Ivanov A, Berezovska O, Hyman BT, McLean PJ. CHIP targets toxic alpha-Synuclein oligomers for degradation. J. Biol. Chem. 283: 17962-17968, 2008.

180. Thompson LM, Aiken CT, Kaltenbach LS, Agrawal N, Illes K, Khoshnan A, Martinez-Vincente M, Arrasate M, O'Rourke JG, Khashwji H, Lukacsovich T, Zhu YZ, Lau AL, Massey A, Hayden MR, Zeitlin SO, Finkbeiner S, Green KN, LaFerla FM, Bates G, Huang L, Patterson PH, Lo DC, Cuervo AM, Marsh JL, Steffan JS. IKK phosphorylates Huntingtin and targets it for degradation by the proteasome and lysosome. J. Cell Biol. 187: 1083-1099, 2009.

181. Tomaru U, Takahashi S, Ishizu A, Miyatake Y, Gohda A, Suzuki S, Ono A, Ohara J, Baba T, Murata S, Tanaka K, Kasahara M. Decreased proteasomal activity causes agerelated phenotypes and promotes the development of metabolic abnormalities. Am. J. Pathol. 180: 963-972, 2012.

182. Tonoki A, Kuranaga E, Tomioka T, Hamazaki J, Murata S, Tanaka K, Miura M. Genetic evidence linking age-dependent attenuation of the $26 \mathrm{~S}$ proteasome with the aging process. Mol. Cell. Biol. 29: 1095-1106, 2009.

183. Tresse E, Salomons FA, Vesa J, Bott LC, Kimonis V, Yao T-P, Dantuma NP, Taylor $\mathrm{JP}$. VCP/p97 is essential for maturation of ubiquitin-containing autophagosomes and this function is impaired by mutations that cause IBMPFD. Autophagy 6: 217-227, 2010.

184. Tseng BP, Green KN, Chan JL, Blurton-Jones M, LaFerla FM. A $\beta$ inhibits the proteasome and enhances amyloid and tau accumulation. Neurobiol. Aging 29: 1607$1618,2008$.

185. Ugarte N, Petropoulos I, Friguet B. Oxidized Mitochondrial Protein Degradation and Repair in Aging and Oxidative Stress. Antioxidants Redox Signal. 13: 539-549, 2010.

186. Um JW, Im E, Lee HJ, Min B, Yoo L, Yoo J, Lübbert H, Stichel-Gunkel C, Cho H-S, Yoon JB, Chung KC. Parkin directly modulates $26 \mathrm{~S}$ proteasome activity. J. Neurosci. Off. J. Soc. Neurosci. 30: 11805-11814, 2010.

187. Urushitani M, Kurisu J, Tateno M, Hatakeyama S, Nakayama K-I, Kato S, Takahashi R. CHIP promotes proteasomal degradation of familial ALS-linked mutant SOD1 by ubiquitinating Hsp/Hsc70. J. Neurochem. 90: 231-244, 2004.

188. Valentine JS, Hart PJ. Misfolded CuZnSOD and amyotrophic lateral sclerosis. Proc. Natl. Acad. Sci. U. S. A. 100: 3617-3622, 2003.

189. Vilchez D, Morantte I, Liu Z, Douglas PM, Merkwirth C, Rodrigues APC, Manning G, Dillin A. RPN-6 determines C. elegans longevity under proteotoxic stress conditions. Nature 489: 263-268, 2012.

190. Vives-Bauza C, Przedborski S. Mitophagy: the latest problem for Parkinson's disease. Trends Mol. Med. 17: 158-165, 2011.

191. Vogiatzi T, Xilouri M, Vekrellis K, Stefanis L. Wild type alpha-synuclein is degraded by chaperone-mediated autophagy and macroautophagy in neuronal cells. J. Biol. 
Chem. 283: 23542-23556, 2008.

192. De Vrij FMS, Fischer DF, van Leeuwen FW, Hol EM. Protein quality control in Alzheimer's disease by the ubiquitin proteasome system. Prog. Neurobiol. 74: 249$270,2004$.

193. Walsh DM, Selkoe DJ. Deciphering the Molecular Basis of Memory Failure in Alzheimer's Disease. Neuron 44: 181-193, 2004.

194. Wang J, Wang C-E, Orr A, Tydlacka S, Li S-H, Li X-J. Impaired ubiquitin-proteasome system activity in the synapses of Huntington's disease mice. J. Cell Biol. 180: 11771189, 2008.

195. Watanabe N, Yamada S. Activation of $20 \mathrm{~S}$ proteasomes from spinach leaves by fatty acids. Plant Cell Physiol. 37: 147-151, 1996.

196. Watts GDJ, Wymer J, Kovach MJ, Mehta SG, Mumm S, Darvish D, Pestronk A, Whyte MP, Kimonis VE. Inclusion body myopathy associated with Paget disease of bone and frontotemporal dementia is caused by mutant valosin-containing protein. Nat. Genet. 36: 377-381, 2004.

197. Webb JL, Ravikumar B, Atkins J, Skepper JN, Rubinsztein DC. Alpha-Synuclein is degraded by both autophagy and the proteasome. J. Biol. Chem. 278: 25009-25013, 2003.

198. Weinberg MS, Samulski RJ, McCown TJ. Adeno-associated virus (AAV) gene therapy for neurological disease. Neuropharmacology 69: 82-88, 2013.

199. Wilk S, Chen WE. Synthetic peptide-based activators of the proteasome. Mol. Biol. Rep. 24: 119-124, 1997.

200. Williams AJ, Knutson TM, Colomer Gould VF, Paulson HL. In vivo suppression of polyglutamine neurotoxicity by C-terminus of Hsp70-interacting protein (CHIP) supports an aggregation model of pathogenesis. Neurobiol. Dis. 33: 342-353, 2009.

201. Wilson SM, Bhattacharyya B, Rachel RA, Coppola V, Tessarollo L, Householder DB, Fletcher CF, Miller RJ, Copeland NG, Jenkins NA. Synaptic defects in ataxia mice result from a mutation in Usp14, encoding a ubiquitin-specific protease. Nat. Genet. 32: 420-425, 2002.

202. Winborn BJ, Travis SM, Todi SV, Scaglione KM, Xu P, Williams AJ, Cohen RE, Peng J, Paulson HL. The Deubiquitinating Enzyme Ataxin-3, a Polyglutamine Disease Protein, Edits Lys63 Linkages in Mixed Linkage Ubiquitin Chains. J. Biol. Chem. 283: 26436-26443, 2008.

203. Xilouri M, Kyratzi E, Pitychoutis PM, Papadopoulou-Daifoti Z, Perier C, Vila M, Maniati M, Ulusoy A, Kirik D, Park DS, Wada K, Stefanis L. Selective neuroprotective effects of the S18Y polymorphic variant of UCH-L1 in the dopaminergic system. Hum. Mol. Genet. 21: 874-889, 2012.

204. Xu E, Tang Y, Li D, Jia J. Polymorphism of HD and UCHL-1 genes in Huntington's disease. J. Clin. Neurosci. 16: 1473-1477, 2009. 
205. Yao D, Gu Z, Nakamura T, Shi Z-Q, Ma Y, Gaston B, Palmer LA, Rockenstein EM, Zhang Z, Masliah E, Uehara T, Lipton SA. Nitrosative stress linked to sporadic Parkinson's disease: S-nitrosylation of parkin regulates its E3 ubiquitin ligase activity. Proc. Natl. Acad. Sci. U. S. A. 101: 10810-10814, 2004.

206. Yao I, Takagi H, Ageta H, Kahyo T, Sato S, Hatanaka K, Fukuda Y, Chiba T, Morone N, Yuasa S, Inokuchi K, Ohtsuka T, Macgregor GR, Tanaka K, Setou M. SCRAPPERdependent ubiquitination of active zone protein RIM1 regulates synaptic vesicle release. Cell 130: 943-957, 2007.

207. Yasuda T, Miyachi S, Kitagawa R, Wada K, Nihira T, Ren Y-R, Hirai Y, Ageyama N, Terao K, Shimada T, Takada M, Mizuno Y, Mochizuki H. Neuronal specificity of alpha-synuclein toxicity and effect of Parkin co-expression in primates. Neuroscience 144: 743-753, 2007.

208. Yasuda T, Nihira T, Ren Y-R, Cao X-Q, Wada K, Setsuie R, Kabuta T, Wada K, Hattori N, Mizuno Y, Mochizuki H. Effects of UCH-L1 on alpha-synuclein overexpression mouse model of Parkinson's disease. J. Neurochem. 108: 932-944, 2009.

209. Ye Y, Shibata Y, Kikkert M, van Voorden S, Wiertz E, Rapoport TA. Recruitment of the p97 ATPase and ubiquitin ligases to the site of retrotranslocation at the endoplasmic reticulum membrane. Proc. Natl. Acad. Sci. U. S. A. 102: 14132-14138, 2005.

210. Yoshii SR, Kishi C, Ishihara N, Mizushima N. Parkin mediates proteasome-dependent protein degradation and rupture of the outer mitochondrial membrane. J. Biol. Chem. 286: 19630-19640, 2011.

211. Zhang F, Hu Y, Huang P, Toleman CA, Paterson AJ, Kudlow JE. Proteasome Function Is Regulated by Cyclic AMP-dependent Protein Kinase through Phosphorylation of Rpt6. J. Biol. Chem. 282: 22460-22471, 2007.

212. Zhang N-Y, Tang Z, Liu C-W. alpha-Synuclein protofibrils inhibit 26 S proteasomemediated protein degradation: understanding the cytotoxicity of protein protofibrils in neurodegenerative disease pathogenesis. J. Biol. Chem. 283: 20288-20298, 2008.

213. Zimprich A, Biskup S, Leitner P, Lichtner P, Farrer M, Lincoln S, Kachergus J, Hulihan M, Uitti RJ, Calne DB, Stoessl AJ, Pfeiffer RF, Patenge N, Carbajal IC, Vieregge P, Asmus F, Müller-Myhsok B, Dickson DW, Meitinger T, Strom TM, Wszolek ZK, Gasser T. Mutations in LRRK2 cause autosomal-dominant parkinsonism with pleomorphic pathology. Neuron 44: 601-607, 2004. 


\section{Tables}

Table 1. Neuropathological hallmarks of neurodegenerative diseases

\begin{tabular}{|c|c|c|c|}
\hline Disease & $\begin{array}{c}\text { Neuropathological } \\
\text { hallmarks }\end{array}$ & Affected brain regions & $\begin{array}{c}\text { Ubiquitinated } \\
\text { inclusions }\end{array}$ \\
\hline $\begin{array}{l}\text { Alzheimer's disease } \\
\text { (AD) }\end{array}$ & $\begin{array}{l}\text { Extracellular A } \beta \text { deposits and } \\
\text { intracellular NFTs }(23,24)\end{array}$ & $\begin{array}{l}\text { Transentorhinal, limbic and } \\
\text { neocortical regions }(23,24)\end{array}$ & + \\
\hline $\begin{array}{l}\text { Parkinson's disease } \\
\text { (PD) }\end{array}$ & $\begin{array}{l}\text { Intracytoplasmic LB composed } \\
\text { of } \alpha \text {-synuclein }(84)\end{array}$ & $\begin{array}{l}\text { Predominantly substantia nigra, } \\
\text { with additional LB pathology in } \\
\text { brainstem and cortical regions ( } 84 \text { ) }\end{array}$ & + \\
\hline $\begin{array}{l}\text { Huntington's disease } \\
\text { (HD) }\end{array}$ & $\begin{array}{l}\text { Intranuclear and intracytoplasmic IB } \\
\text { composed of mtHtt (157) }\end{array}$ & $\begin{array}{c}\text { Predominantly striatum, with } \\
\text { additional atrophy of cerebral } \\
\text { cortex and subcortical white matter } \\
\text { (157) }\end{array}$ & + \\
\hline $\begin{array}{l}\text { Amyotrophic lateral } \\
\text { sclerosis } \\
\text { (ALS) }\end{array}$ & $\begin{array}{l}\text { Intranuclear and intracytoplasmic } \\
\text { aggregates of ALS-associated proteins } \\
\text { (e.g. SOD1, FUS, TDP-43) (44) }\end{array}$ & $\begin{array}{l}\text { Cortical, bulbar and spinal } \\
\text { motor neurons ( } 44)\end{array}$ & + \\
\hline Prion diseases & $\begin{array}{l}\text { Intracytoplasmic and extracellular } \\
\text { deposition of } \operatorname{PrP}^{S c}(177)\end{array}$ & $\begin{array}{c}\text { Heterogeneous distribution } \\
\text { including cortex, cerebellum, } \\
\text { striatum, thalamus, hippocampus } \\
\text { and brainstem ( } 90)\end{array}$ & + \\
\hline
\end{tabular}


Page 55 of 61

Figure legends

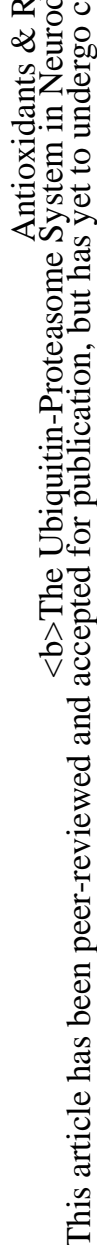




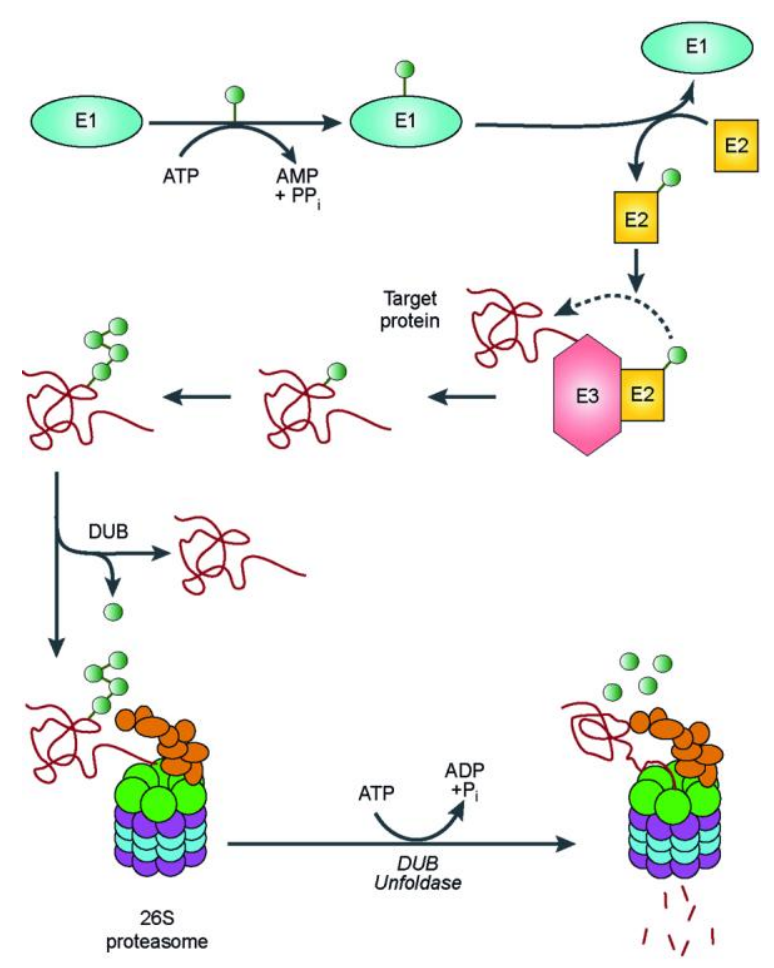

\section{Figure 1. The Ubiquitin-Proteasome System}

Ubiquitin is activated by the ubiquitin-activating enzyme E1, generating a high-energy thiol ester intermediate. Ubiquitin is next transferred, still as a high-energy intermediate, to an ubiquitin-conjugating enzyme, E2. From E2, ubiquitin is covalently attached to an internal lysine residue of a target protein that is bound specifically to an E3 ligase. By a similar mechanism, successive addition of ubiquitin moieties to the previously conjugated one generates a polyubiquitin chain. Ubiquitin conjugation is reversible by the action of DUBs. Polyubiquitin chains are recognised by the $26 \mathrm{~S}$ proteasome as a degradation signal. This enzyme complex unfolds the substrate in an ATP-dependent manner, recycles conjugated ubiquitin moieties by the action of proteasome-associated DUBs and lastly degrades the target protein into short peptides. (To see this illustration in color the reader is referred to the web version of this article at www.libertonline.com/ars). 


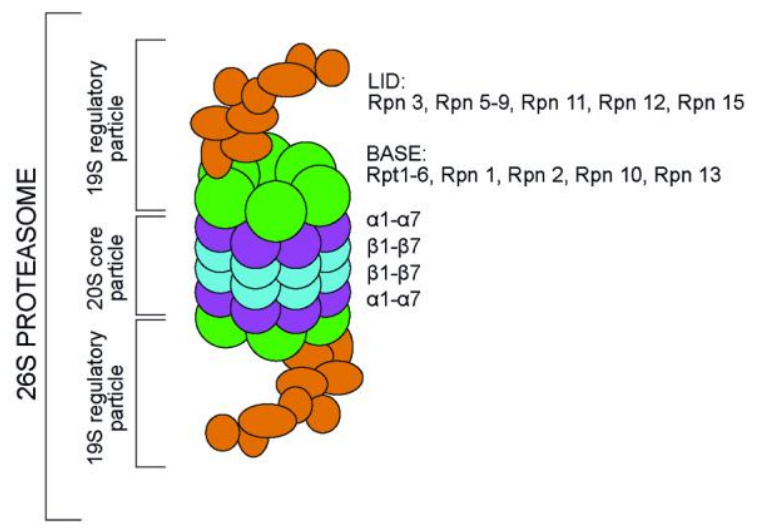

\section{Figure 2. The $26 \mathrm{~S}$ proteasome}

The $26 \mathrm{~S}$ proteasome consists of the catalytic $20 \mathrm{~S}$ core particle, comprising four stacked rings (two outer $\alpha$-rings and two inner $\beta$-rings) and one or two $19 \mathrm{~S}$ regulatory particle(s). The regulatory particle is composed of lid and base subcomplexes, which contain regulatory particle triple-A (Rpt) and regulatory particle non-ATPase (Rpn) subunits. (To see this illustration in color the reader is referred to the web version of this article at www.libertonline.com/ars). 


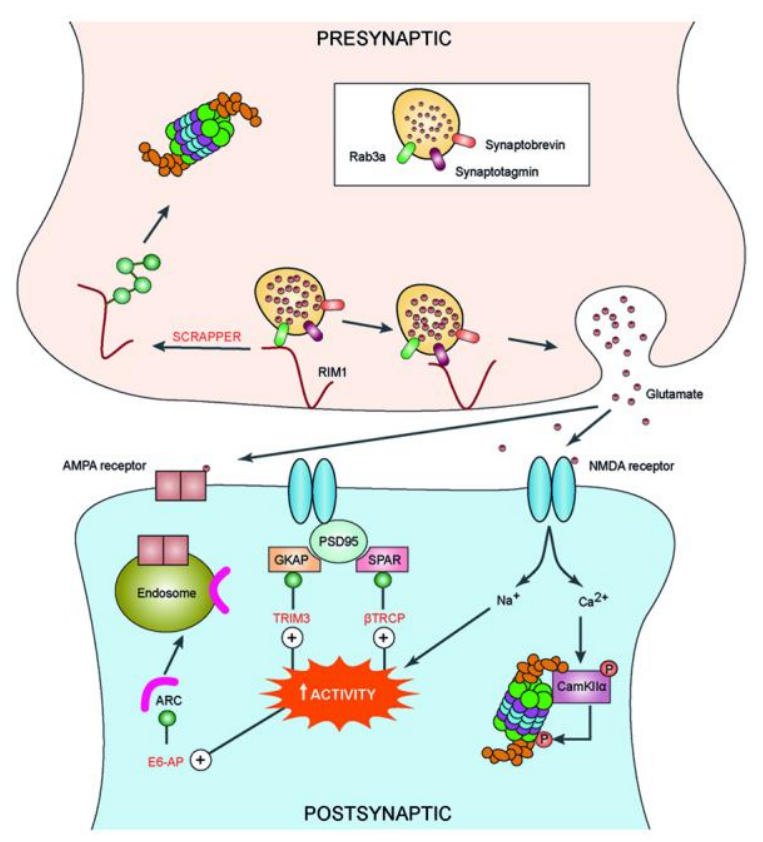

\section{Figure 3. UPS-mediated degradation of proteins in synaptic plasticity}

A schematic diagram of the UPS pathways that regulate synaptic plasticity (see text for details). The release of neurotransmitters from presynaptic terminals by synaptic vesicle exocytosis results in stimulation of post-synaptic NMDA and AMPA glutamate receptors. The E3 ligase SCRAPPER mediates the ubiquitination and degradation of the presynaptic vesicle priming factor RIM1, negatively regulating neurotransmitter release. Activation of NMDA receptors triggers ubiquitination of synaptic scaffold proteins and recruitment of proteasomes to dendritic spines by interaction with autophosphorylated CAMKII $\alpha$, which also enhances proteolytic activity by phosphorylation of Rpt6. Increased neuronal activity results in internalisation of AMPA receptors by E6-AP mediated degradation of Arc. (To see this illustration in color the reader is referred to the web version of this article at www.libertonline.com/ars). 


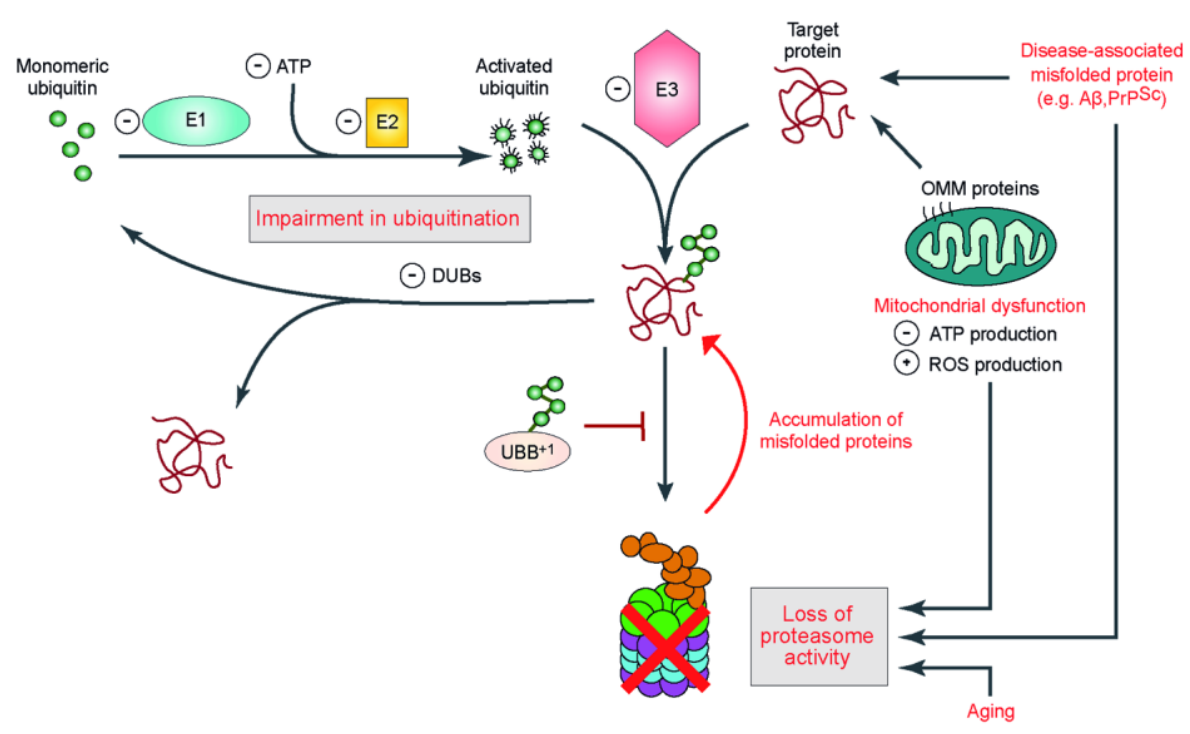

Figure 4. Dysfunction of the UPS in neurodegenerative disease

Dysfunction of the UPS can arise from impairments in ubiquitination due to depletion or reduced activity of E1, E2 or E3 enzymes. In addition, impaired degradation of target proteins can arise from direct inhibition of proteasome activity by disease-associated misfolded proteins, aggravated by an age-related decline in catalytic activity. Secondary impairment of the proteasome can occur in conditions of mitochondrial dysfunction, due to depletion of ATP and production of ROS. Loss of proteasome activity results in the accumulation of misfolded proteins, which can further impair catalytic activity. (To see this illustration in color the reader is referred to the web version of this article at www.libertonline.com/ars). 


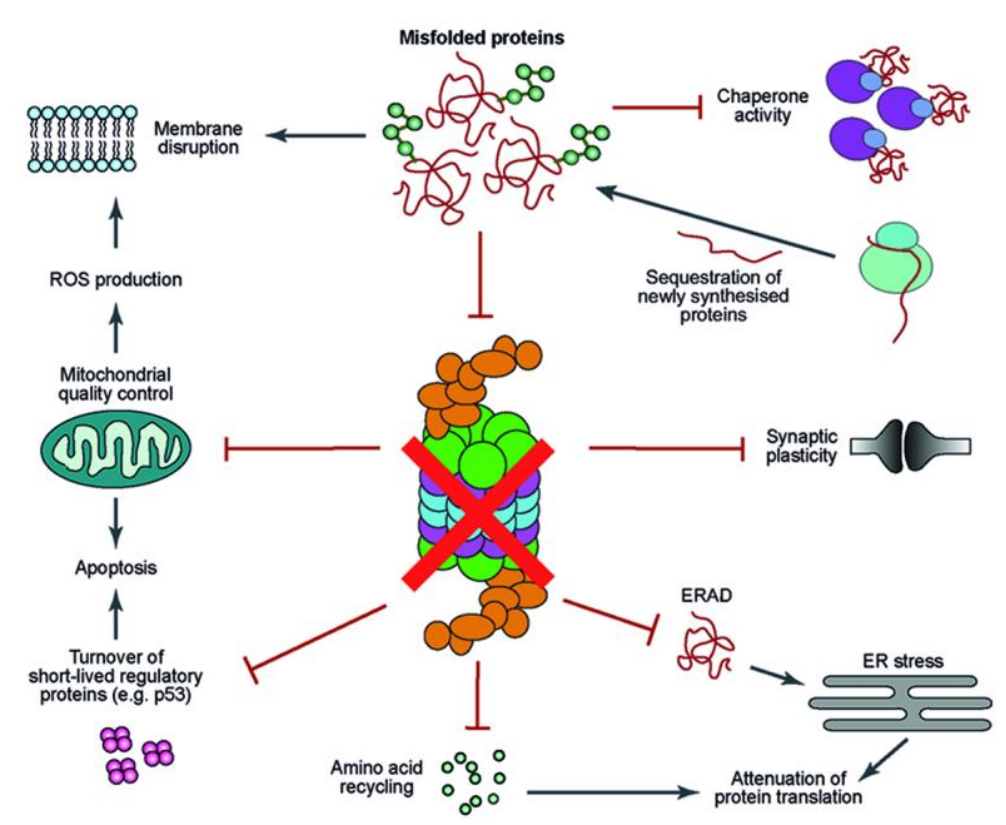

Figure 5. Neurotoxic sequelae of UPS dysfunction

Dysfunction of the UPS is associated with widespread disruption of cellular homeostasis. Due to its critical role in the degradation of synaptic proteins, impairment of the UPS is associated with a loss of synaptic plasticity. Progressive accumulation of misfolded proteins can overwhelm molecular chaperones, leading to the delayed maturation of other chaperoneclients (81). $\beta$-sheet rich disease-associated proteins can also sequester newly-synthesised proteins, many of which occupy critical hub positions in cellular protein networks (143). The exposure of interior hydrophobic residues in misfolded proteins can disrupt biological membranes leading to reduced cellular viability. Due to its critical role in the degradation of OMM proteins, impairments of the UPS can lead to a loss of mitochondrial quality control, leading to production of ROS and apoptosis. A pro-apoptotic state can also arise from the accumulation of short-lived regulatory proteins such as p53. Proteasome failure is associated with a depletion of amino acids (173) and impairment of the ER-associated protein degradation (ERAD) pathway, which can ultimately lead to a lethal attenuation of protein translation. (To see this illustration in color the reader is referred to the web version of this article at www.libertonline.com/ars). 


\begin{tabular}{cc}
\hline Disease & $\begin{array}{c}\text { Neuropathological } \\
\text { hallmarks }\end{array}$ \\
\hline $\begin{array}{c}\text { Alzheimer's disease } \\
(A D)\end{array}$ & $\begin{array}{c}\text { Extracellular A } \beta \text { deposits and } \\
\text { intracellular NFTs }(23,24)\end{array}$ \\
& \\
Parkinson's disease & Intracytoplasmic LB composed \\
$(P D)$ & of $\alpha$-synuclein $(84)$
\end{tabular}

Huntington's disease (HD)

Intranuclear and intracytoplasmic IB composed of mtHtt (157)

Amyotrophic lateral sclerosis (ALS)

Prion diseases Intracytoplasmic and extracellular
deposition of PrPsc (177)
Affected brain regions

Ubiquitinated inclusions

\section{Transentorhinal, limbic and} neocortical regions $(23,24)$

Predominantly substantia nigra, with additional LB pathology in brainstem and cortical regions (84)

Predominantly striatum, with additional atrophy of cerebral cortex and subcortical white matter

(157)

$$
\begin{aligned}
& \text { Cortical, bulbar and spinal } \\
& \text { motor neurons (44) }
\end{aligned}
$$

Heterogeneous distribution including cortex, cerebellum, striatum, thalamus, hippocampus and brainstem (90)

$<\mathrm{b}>$ Table 1 . Neuropathological hallmarks of neurodegenerative diseases $</ \mathrm{b}>$ 